1

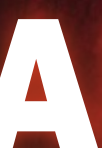

Ri:

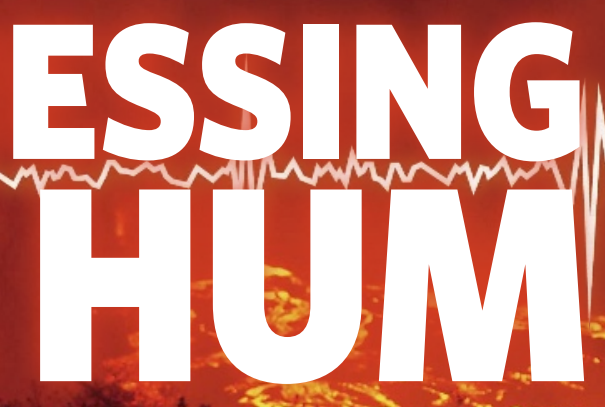

athis

A new way to analyse seismic vibrations is bringing order out of noise to help predict volcanic eruptions or create detailed wy images of Earth's interior. Rachel Courtland reports.
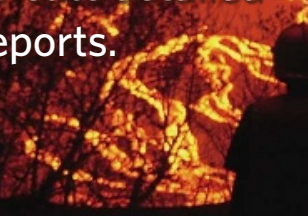
images of Earth's interior. Rachel Courtand $19 \mathrm{C}$
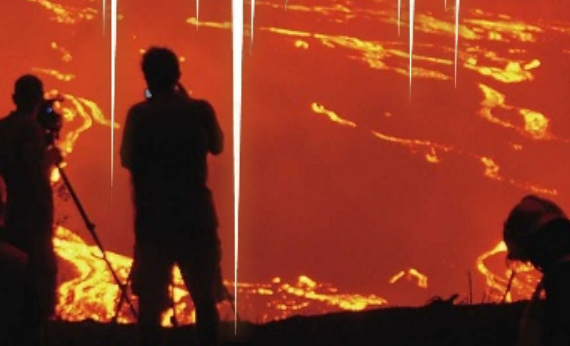

The research started to take off in 1999, when

works for seismically quiet areas that do not routinely see the earthquakes needed for traditional imaging studies.

Seismologist Andrew Curtis of the University of Edinburgh, UK, says that using the technique is like discovering an unknown continent. "An incredible new area of exploration has come upon us," he says.

\title{
Noisy beginnings
}

Random noise has long been used to tease out the intrinsic properties of materials. The theoretical underpinnings trace back to the 'fluctuation-dissipation theorem', formulated in 1928 to describe how noise in an electrical signal can reveal a material's response to current. The theorem suggests that, with proper analysis, random vibrations inside Earth could act like seismic waves, revealing structure and hinting

"The idea is that in waves that are fully garbled, there is still some sort of residual coherence."

\section{- Richard Weaver} \section{from all dir} ple times in Earth's interior. On a seismograph, they show up as a seemingly meaningless series of spikes and troughs. Yet over the past few years, seismologists have transformed the hum from a nuisance to a powerful tool to image Earth's crust and upper mantle.

The new field, known as ambient-noise tomography, has several advantages over traditional seismic imaging. Its improved resolution may help to answer some persistent geological questions. It also means that researchers do not have to wait for one-off events such as earthquakes, opening up the possibility of imaging Earth's crust over time. In addition, the technique at properties such as temperature, composition, orientation and stress.

All noise passing through Earth must pass through the same internal structures, and hence each signal - although inherently random - retains a sort of 'memory' of the material it has passed through. So by looking at correlations in noise between two seismometers, researchers can extract information on the material lying between the pair. "The idea is that in waves that are fully garbled, there is still some sort of residual coherence," says Richard Weaver, a physicist at the University of Illinois at Urbana-Champaign.
I'm not so sure why I was so confident."

After the workshop, the two went off to investigate how the technique could be used to probe the properties of materials. As a proof of principle, Weaver showed that ambient ultrasound vibrations in aluminium could be used to determine the material's elastic properties ${ }^{1}$. Then Campillo applied the same technique to the earthquake coda; the noise seemed to be correlated just as he hoped it would be ${ }^{2}$. So Campillo began to eye the ambient noise that dominates seismographs when the codas fade, in the hope of quickly and finely imaging the crust. It worked.

In 2005, two teams ${ }^{3,4}$, one of which included 
Campillo and his colleagues, used ambient noise to construct three-dimensional maps of seismic-wave speeds in southern California. The images had a horizontal resolution as small as 60 kilometres, more than four times the detail in traditional earthquake tomography.

The success of the technique was a surprise to Campillo. Seismic noise on the California coast is lopsided, as the eastward-moving waves from the Pacific Ocean tend to swamp noise from other directions. "If you want to use the
"It was not at all obvious that noise would work." - Michel Campillo
Thorne Lay, an Earth scientist at the University of California, Santa Cruz.

To investigate, Rob van der Hilst of the Massachusetts Institute of Technology in Cambridge and his colleagues set up 25 seismometer stations on the eastern edge of the plateau, then combined data from ambient noise and traditional tomography to produce a picture of the plateau down to a depth of 280 kilometres ${ }^{5}$. The clearest images, which came from ambient tomography done roughly 50 kilometres down, noise, you have to assume the noise has the right properties, that there is an even distribution of sources," says Campillo. "And of course that's not true - it was not at all obvious that noise would work as well."

Most of Earth's ambient noise reverberates through the shallower parts of the planet, making the technique most useful in the upper 60 kilometres of Earth. But since 2005, several teams have used the technique to look deeper into Earth's crust - and even into the upper mantle.

\section{Collisions to climates}

Paradoxically, some of the clearest pictures of those depths come from the highest plateau on Earth, the Qingzang Gaoyuan plateau (often referred to as the Tibetan plateau). At an average elevation of 4.5 kilometres above sea level, the plateau is being pushed ever-higher by the ongoing collision between the Indian and Eurasian continental plates. The thickest part is on the eastern side of the plateau, where the crust is roughly 80 kilometres thick - twice the average for the continental crust. Working out exactly how and when the plateau got so high could help to improve climate models, as some researchers posit that the arrival of Indian monsoons coincided with the rise of the eastern side of the plateau.

Geologists are also still debating how the crust on the eastern side grew so thick. One theory holds that it thickened as it was squeezed against the stronger crust of the neighbouring Sichuan basin. Others think that the crust from the Indian subcontinent is largely responsible, pushing and flowing through the plateau, inflating it like a tire. "It's sort of a conservation of mass problem. You're shoving one continent into the belly of another continent, and you want to know where all the mass goes," says

showed chopped-up areas where seismic waves travelled slower than usual. These low-velocity regions may be weak parts of the crust that have slowly flowed underneath and between other crustal layers. Although the images cover too small an area to be definitive, Lay says, "it's a step in the right direction".

Proponents of the flow model are encouraged.
IN THE HEART OF A VOLCANO

An ambient-noise image of the ground beneath the Piton de la Fournaise volcano on Réunion Island reveals a region where seismic waves sped up, delineating what may be a chimney of solid magma.
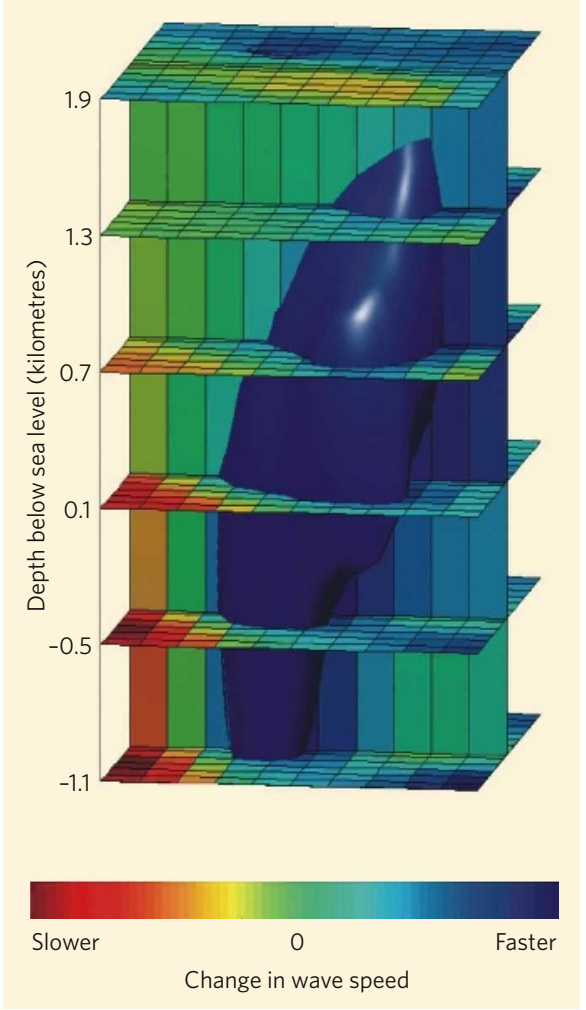

"I would say it's very new, exciting evidence. We didn't know there were low-velocity zones down there at all," says van der Hilst's colleague Leigh Royden, whose model of the plateau's uplift predicts crustal flow. The results also suggest that the model of crustal flow is more complicated than originally expected; the weak parts do not form a uniform, flowing layer, suggesting a complex network of conduits where the crust flows through the middle and lower mantle.

Later this year, van der Hilst plans to return to the area to collect data from a recently installed Chinese array of 300 seismometers. The additional data will help to improve resolution and might also help to differentiate between seismic speeds in different directions. This directional dependence, or anisotropy, may hint at material under strain, an indicator of flow.

\section{Early warning}

The wealth of data offered by ambient noise tomography may also assist in more dynamic measurements, such as detecting precursors of volcanic eruptions. For the past several years, Campillo and his colleagues have set their sights on Piton de la Fournaise, an active volcano poised on the edge of the island of Réunion, near Madagascar. Piton de la Fournaise runs almost like clockwork: Averaged over the last 200 years, it has erupted every 10 months. Although most of the island's roughly 800,000 inhabitants live beyond the volcano's reach, past eruptions have overflowed the caldera, reaching the ocean as well as villages.

Over the years, seismologists have used Piton de la Fournaise as a test bed for several techniques that might help to predict future eruptions. Most rely on geodetics - sensors that measure strain, tilt or displacement on the surface of the volcano to detect slight changes, such as bulging from pent-up pressure. Seismometers are also set to look for any increase in shaking that might signal an impending explosion.

But in the absence of shaking, which sometimes starts just days or hours before an eruption, the volcano is a black box. "Seismic activity is less reliable for volcano eruption forecasting, because it can be linked to a lot of phenomena," says Florent Brenguier at the Institute of Earth Physics in Paris. "It is not a clear sign of an oncoming collapse."

Last year, Brenguier and his colleagues showed that 18 months of data from 21 seismometers scattered around the volcano could 
be used to reconstruct its three-dimensional structure $^{6}$. The images showed a unique structure that matched up with previous experiments: an anomalous area of high velocity, one kilometre east of the volcano's main vent, which seems to be a chimney full of solidified magma. Unexpectedly, comparing images separated by several months showed that seismic waves slowed down by a tiny amount $-0.1 \%$ - when travelling through this structure.

What's more, the waves started to slow down as early as 20 days before four eruptions that occurred between July 1999 and December 2000. Clear indicators of the change in speed showed up 5 days before the eruption. Why this happened isn't clear, but Brenguier says the speed changes probably match up with the opening of fissures within the edifice, through which the magma eventually flows to the surface.

But there are challenges in trying to use ambient noise to predict volcanic eruptions. For one thing, seismic waves in Piton de la Fournaise also show long-term changes in their speed, which may stem from mechanical changes due to tides or fluctuations in water level. "We don't know at the moment how to correct for these long-term variations or how they could be used for real-time monitoring," says Brenguier. The team's latest data, though, suggest that large changes in wave velocity correspond to larger eruptions, and down the line it might at least be

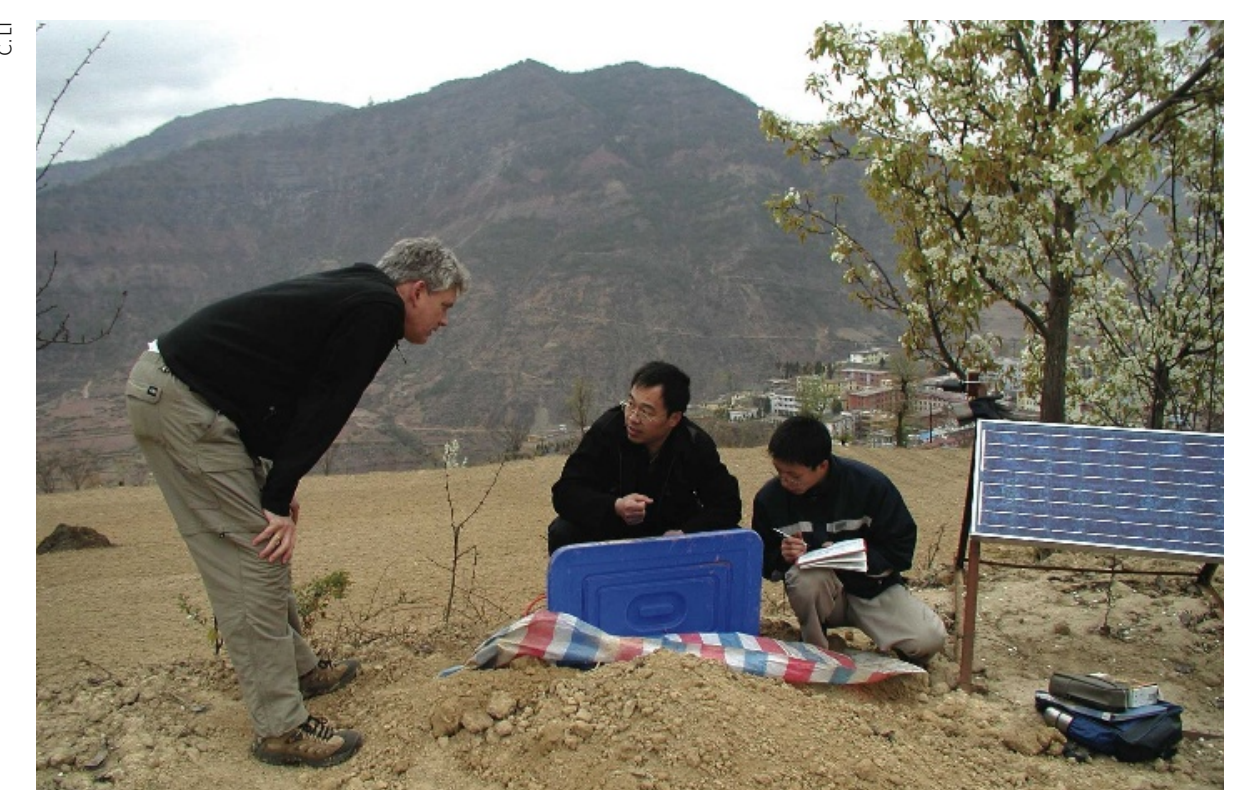

Rob van der Hilst and his colleagues use ambient noise and traditional tomography to image Earth's crust.

possible to predict the size of an eruption ${ }^{7}$.

Bernard Chouet, a volcanologist at the US Geological Survey in Menlo Park, California, questions whether warnings from ambient noise will ever be better than the few days' notice researchers typically get from the longperiod seismic events generated when magma starts to gurgle in a volcano. But, he says, "all these things put together are going to put us closer to forecasting things more precisely". Extending the technique to volcanoes with more irregular eruptions will be a crucial test; such studies

"This is ultimately going to put the emphasis on processes rather than structures."

\section{- Michael Ritzwoller} are already under way, including one at Mount Merapi in Indonesia.

\section{Graphic detail}

In the years to come, the true bounty of ambient noise tomography may lie in high-resolution, three-dimensional maps of large swaths of Earth's crust, rather than having to wait for earthquakes. Some of the most detailed maps produced so far with this technique have come from the western United States.

In the past few years, researchers have studied ambient noise using USArray, which includes a rolling grid of 400 transportable seismometers that began mapping the west coast in 2004, but are moved eastwards each year. USArray was

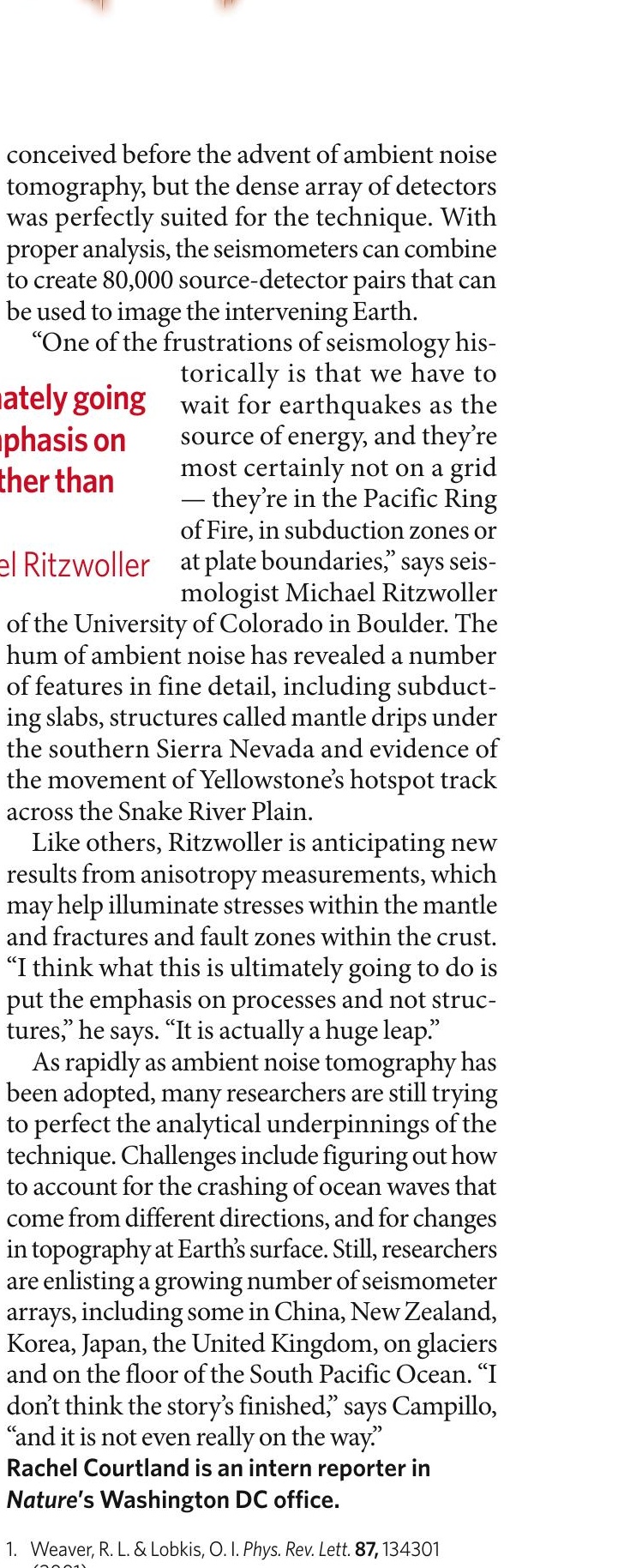

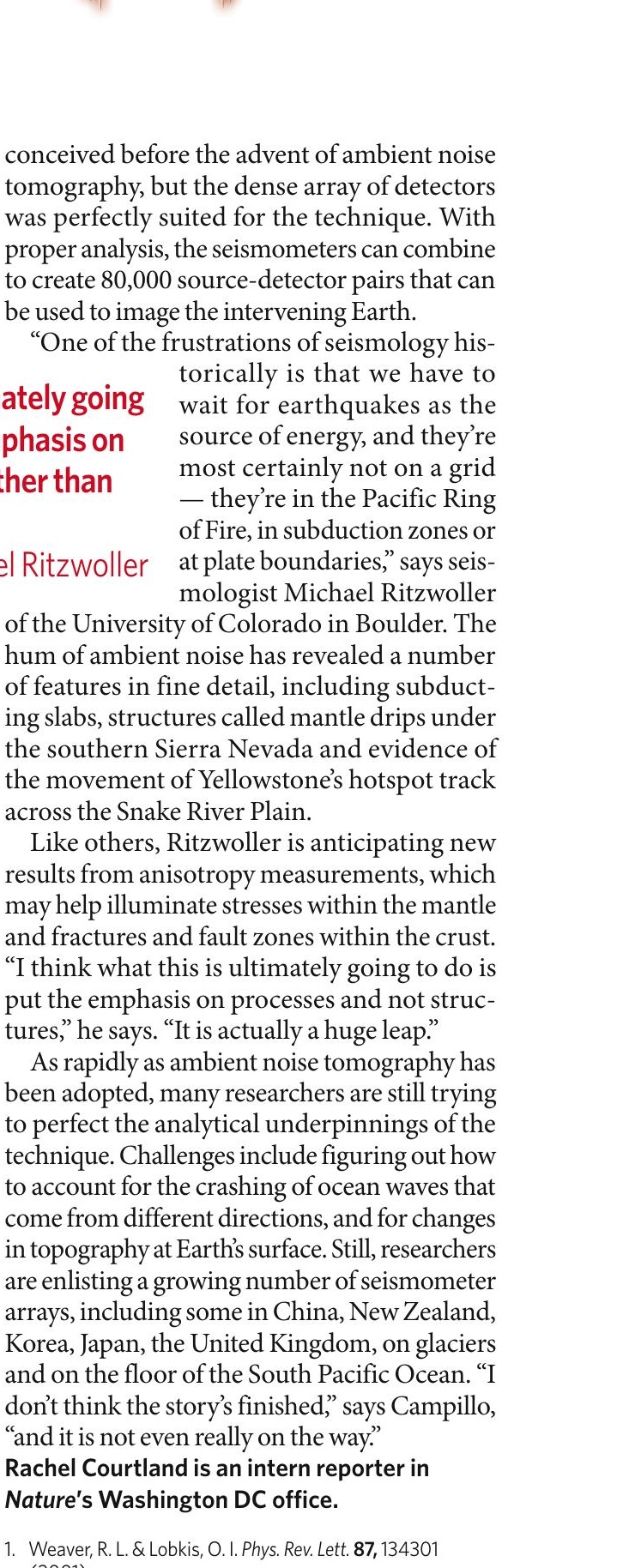

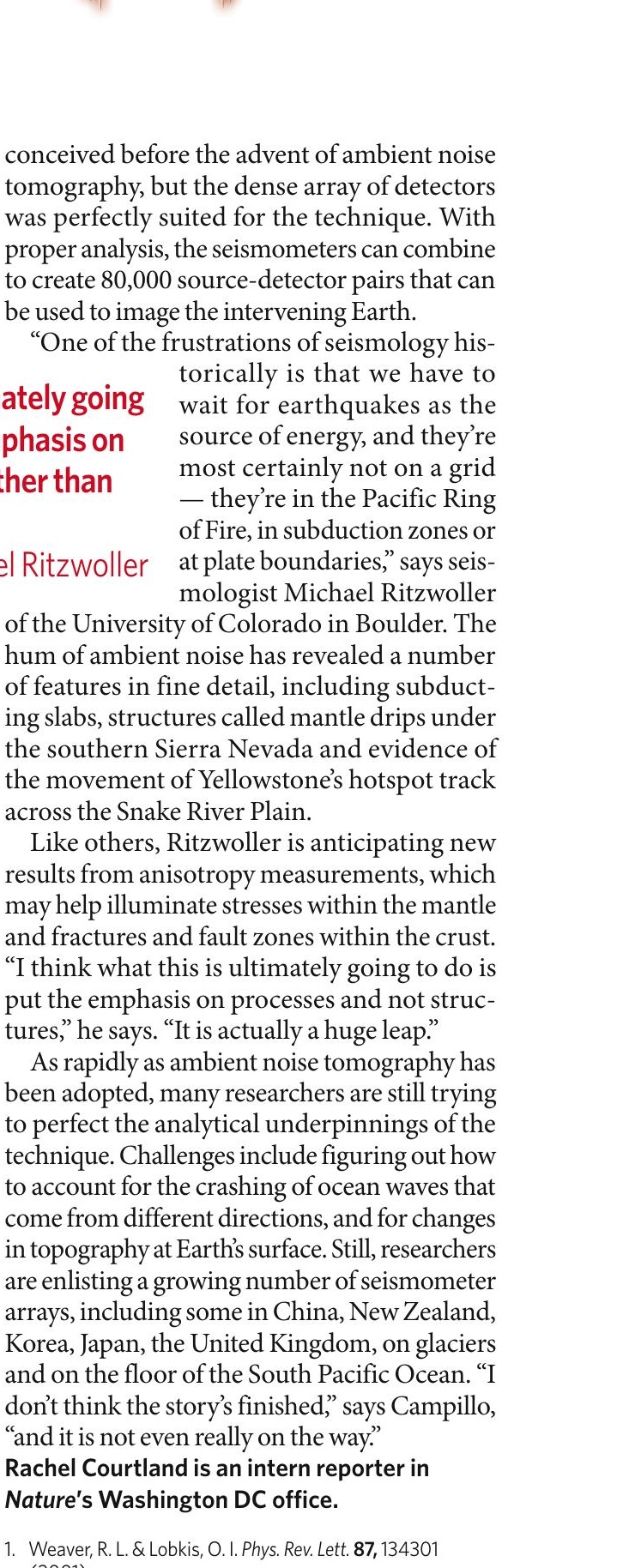

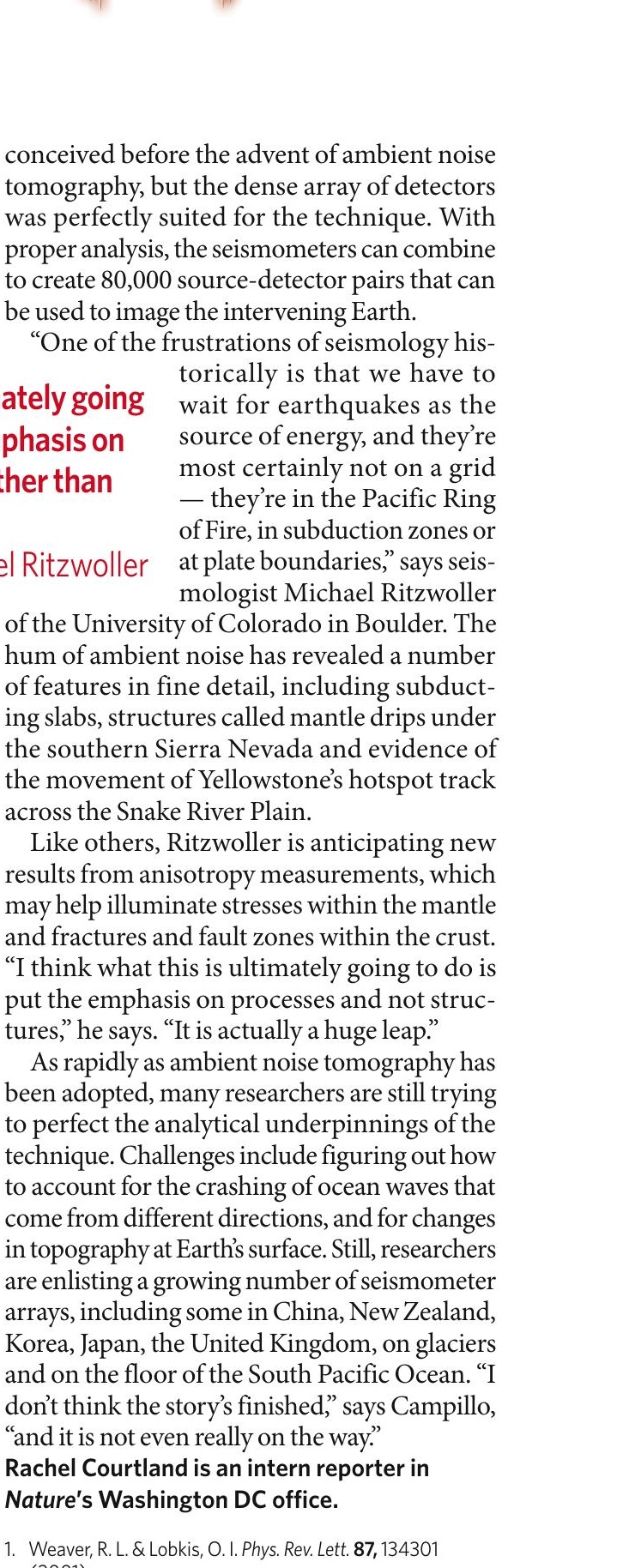

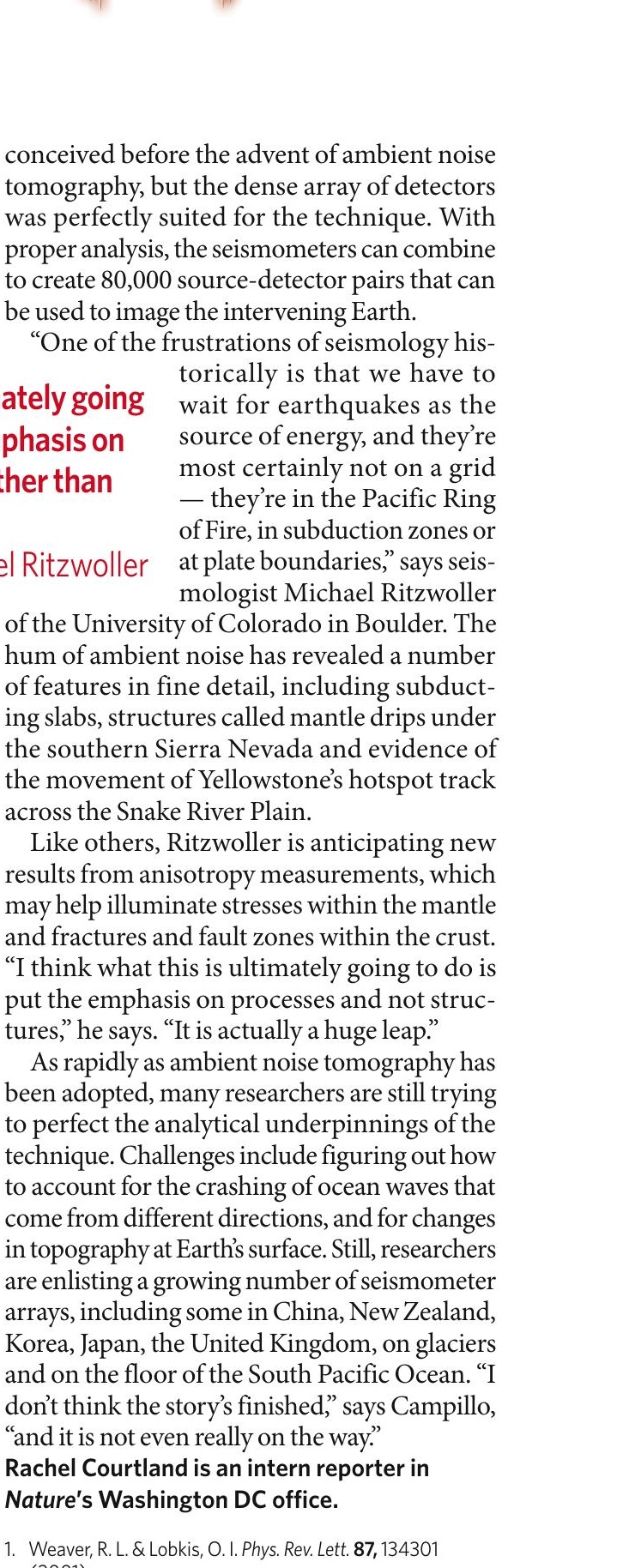

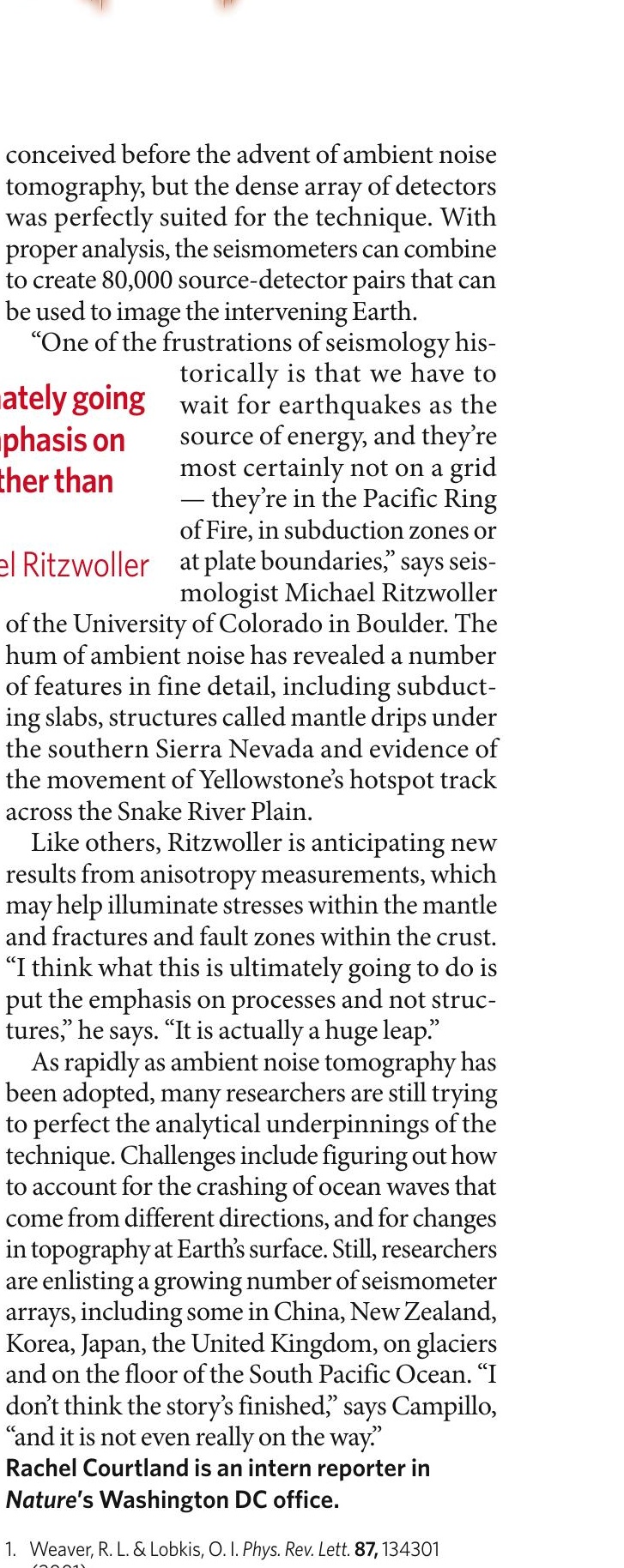

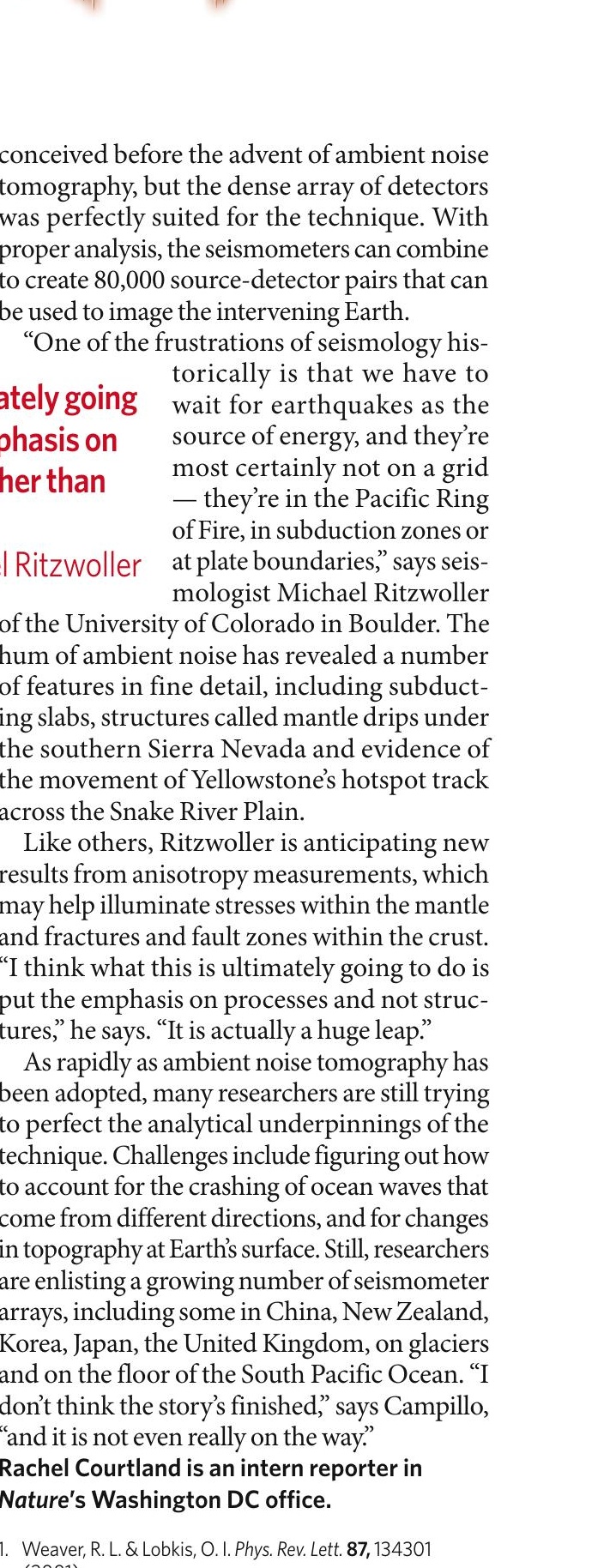

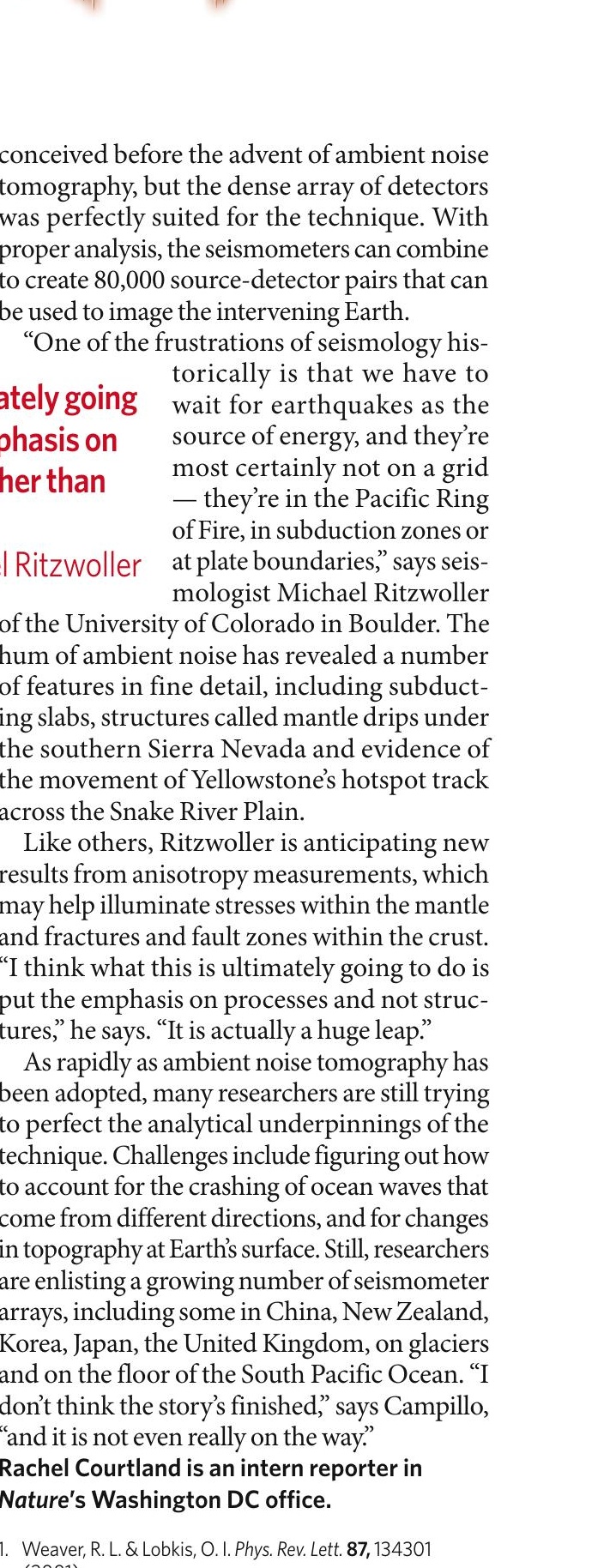

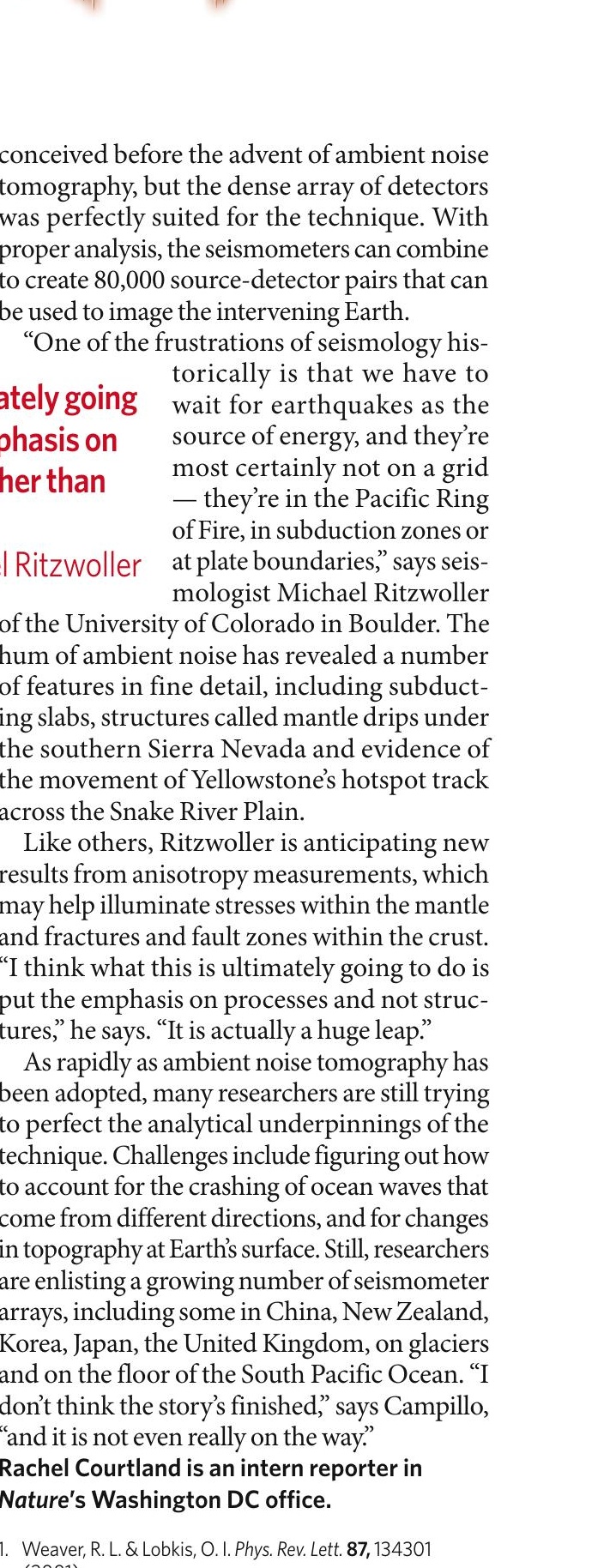

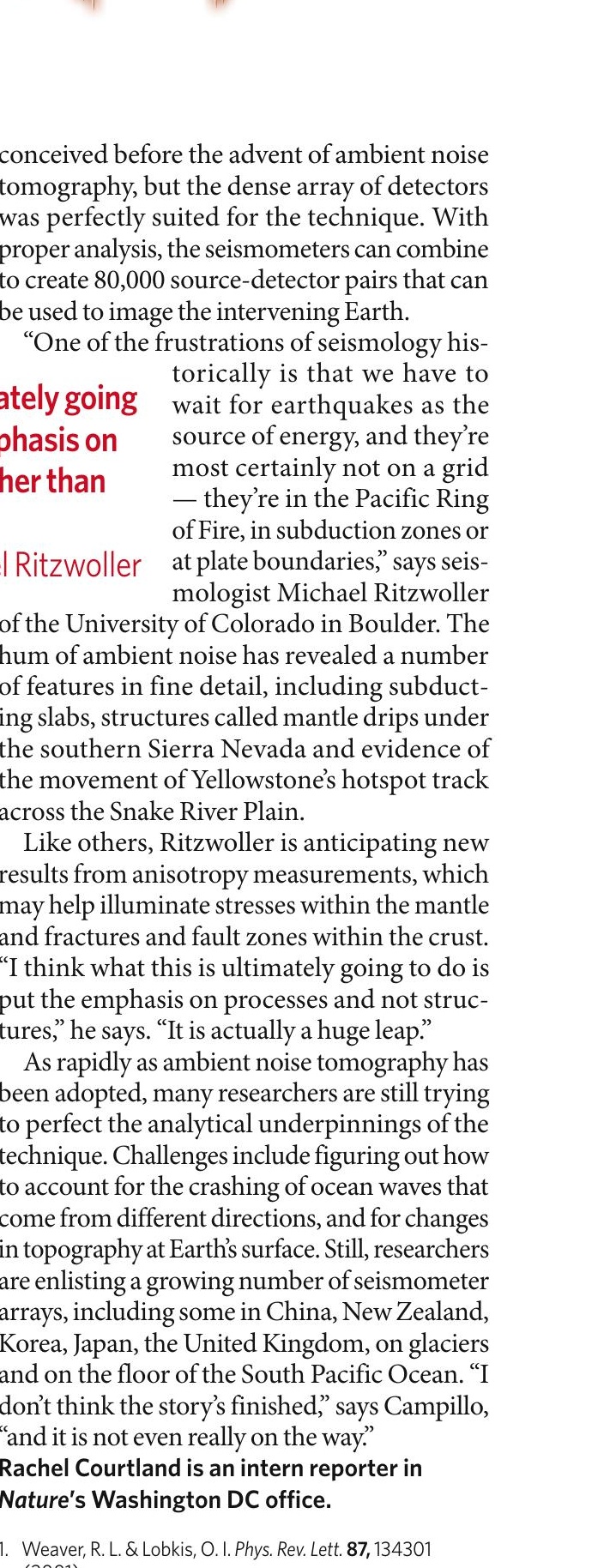

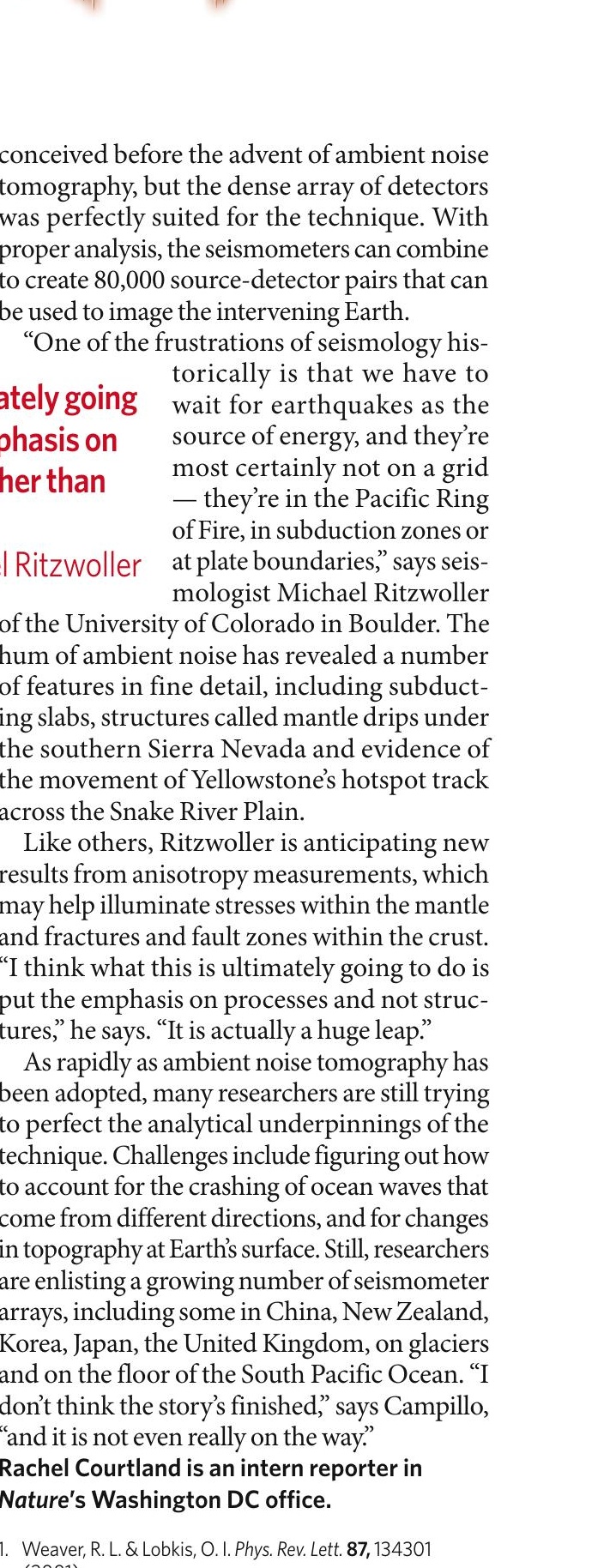

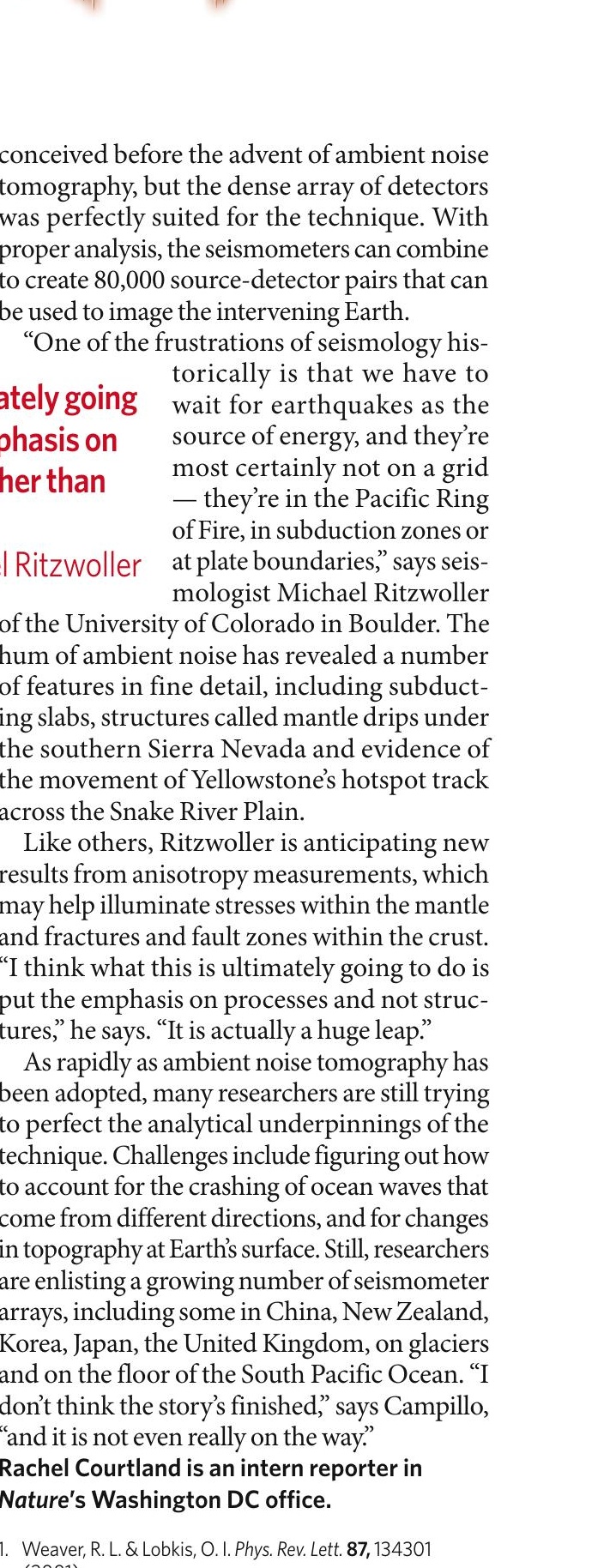

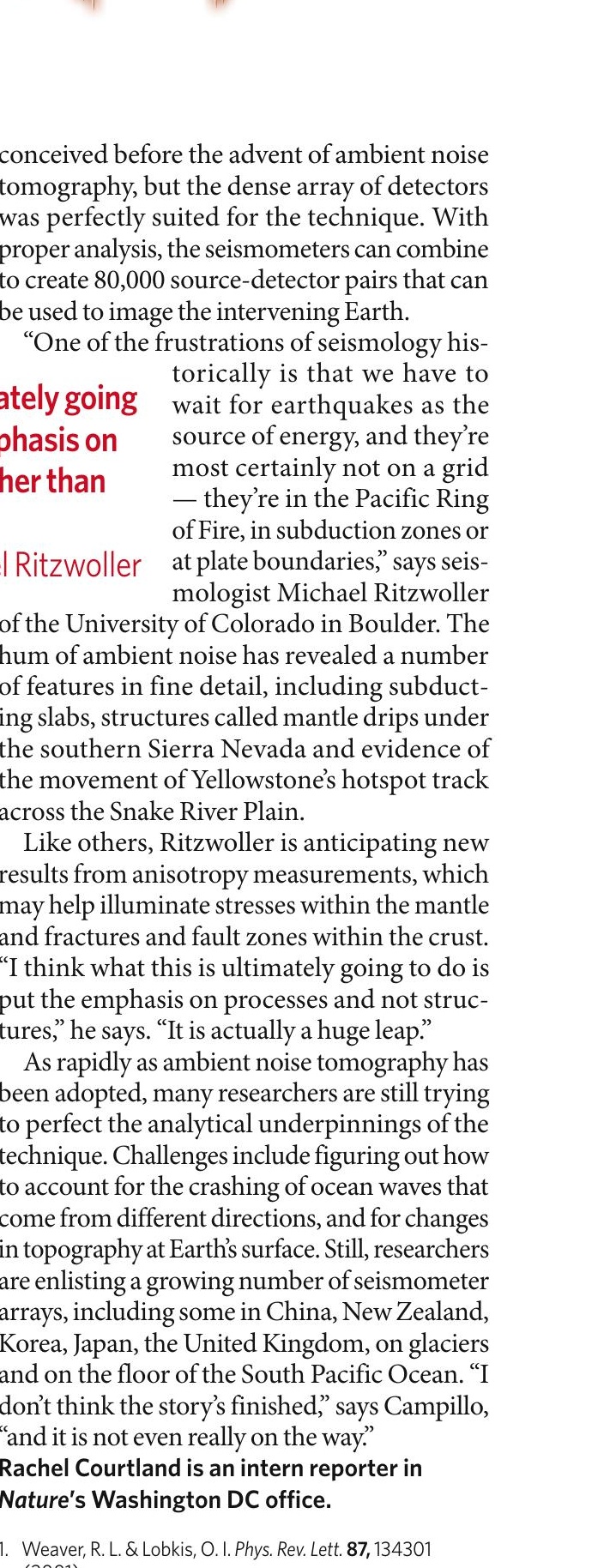

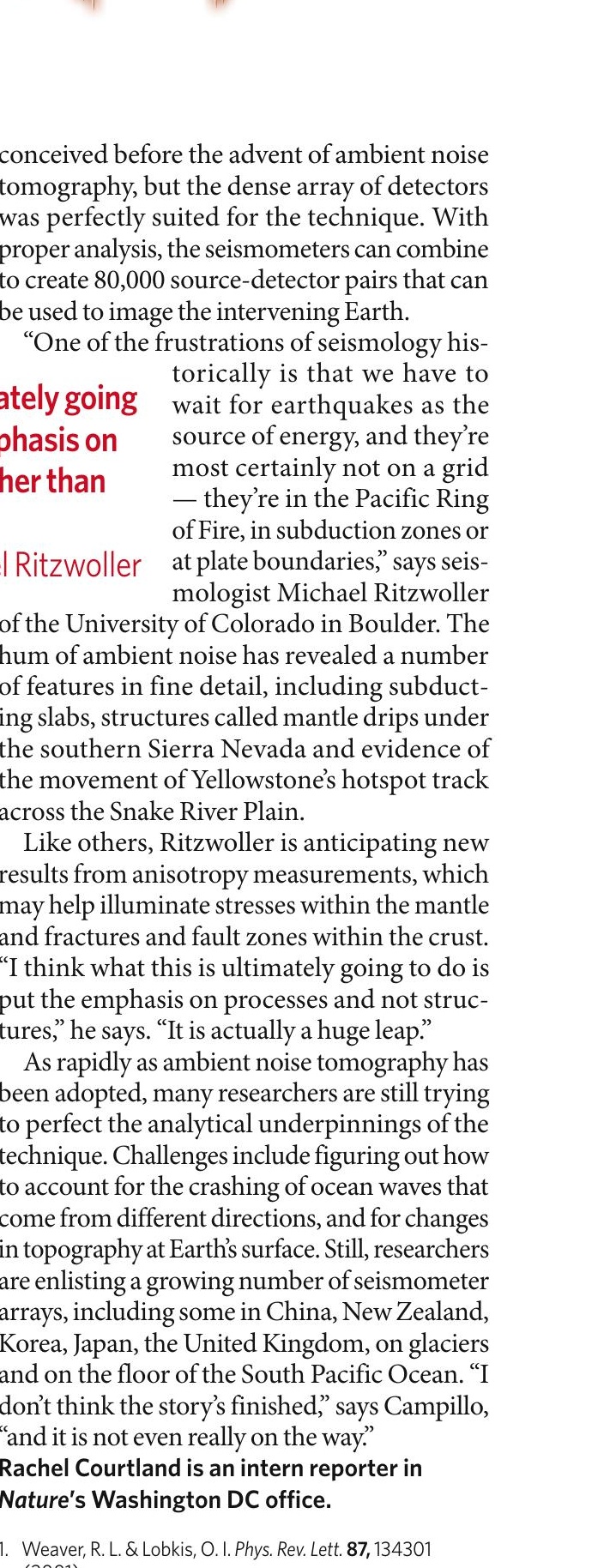

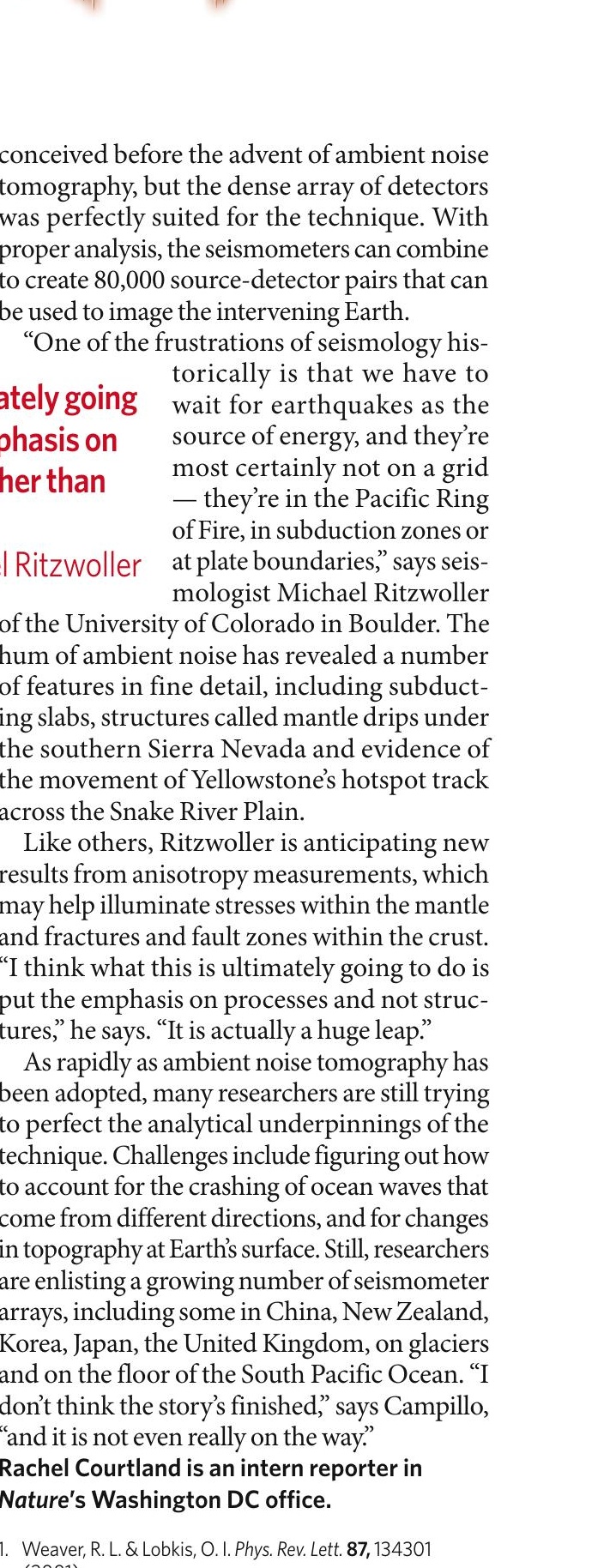

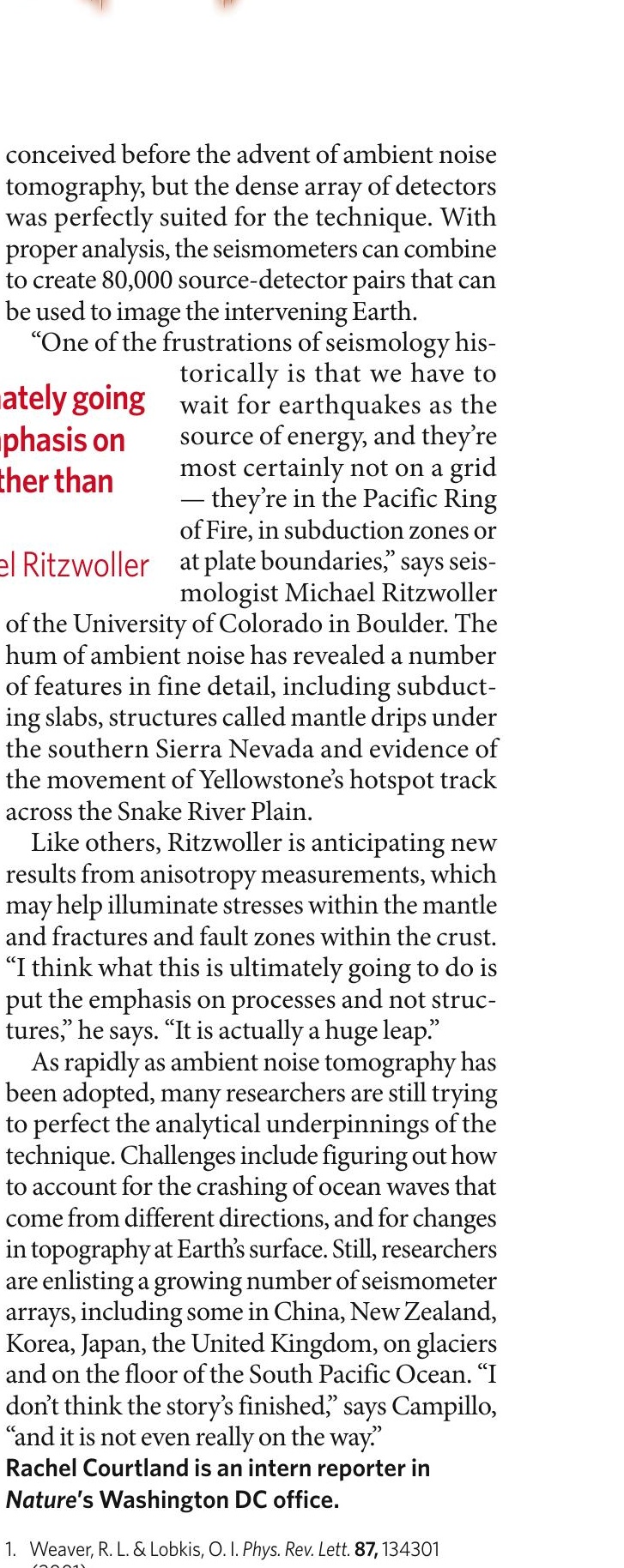

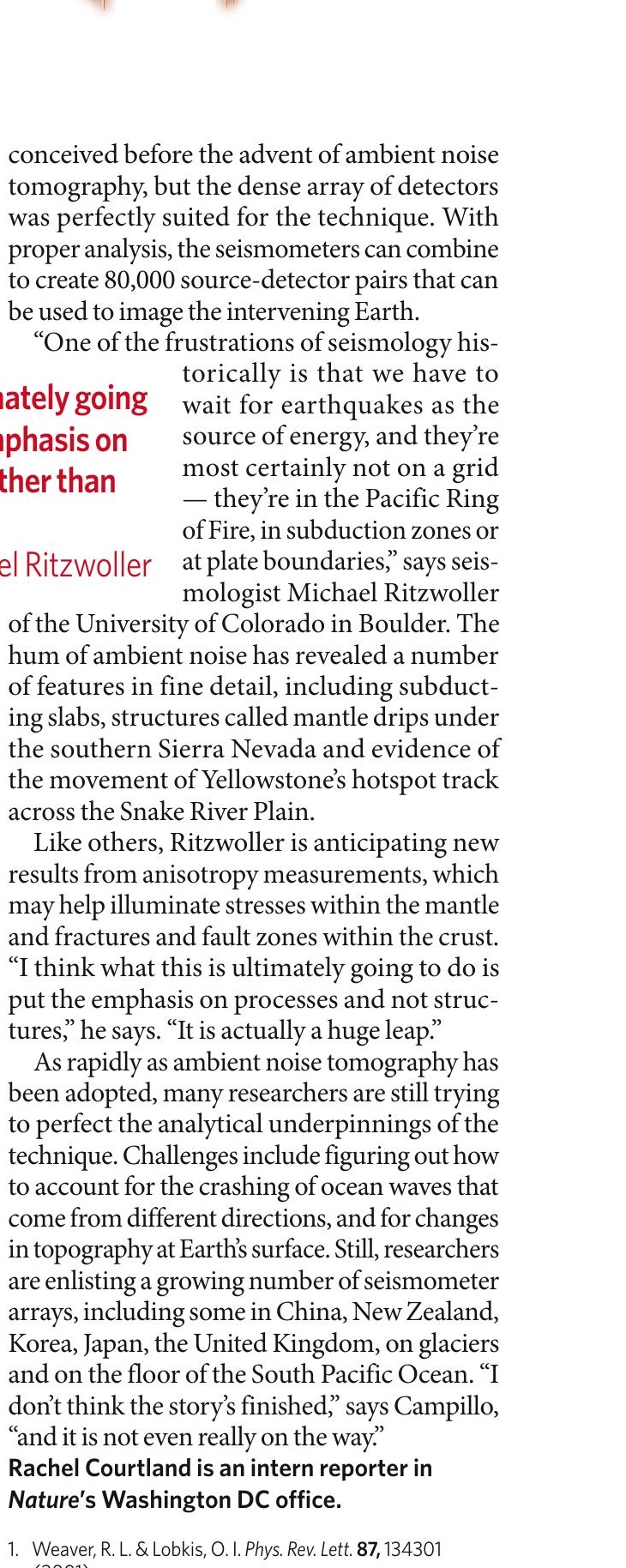

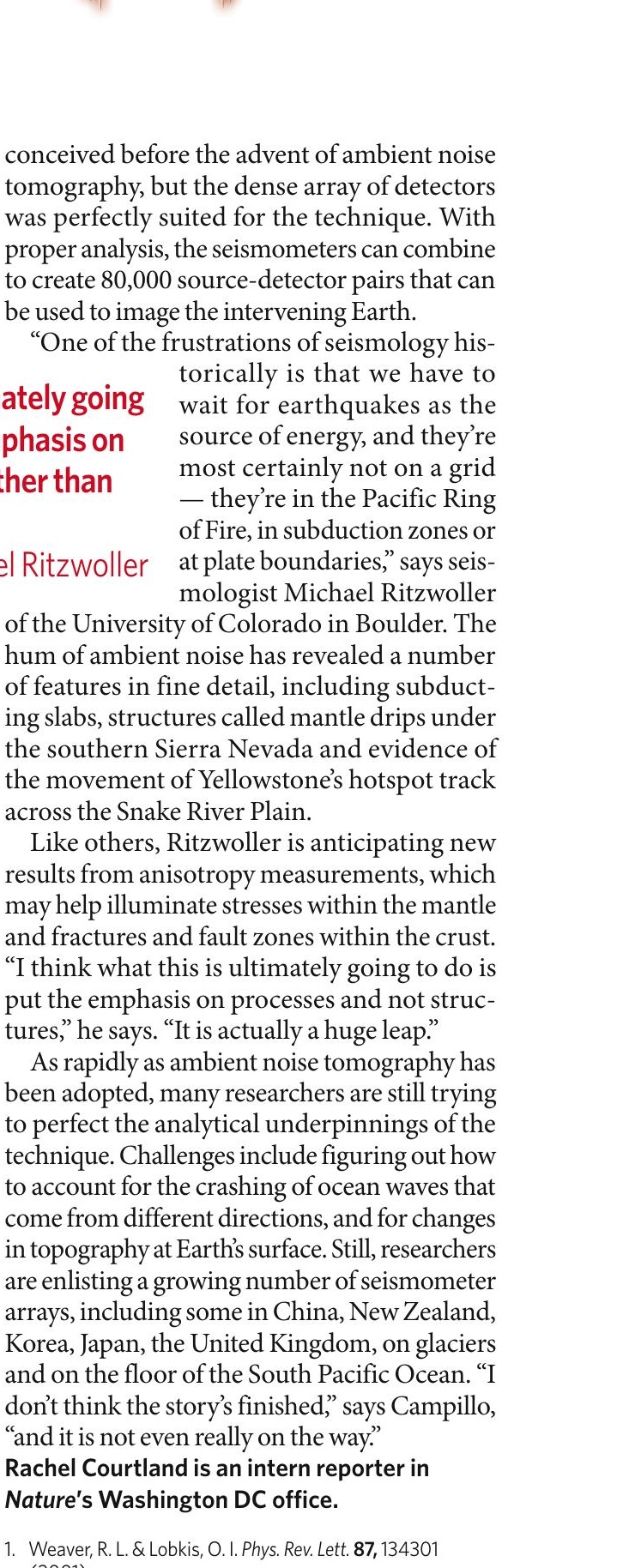

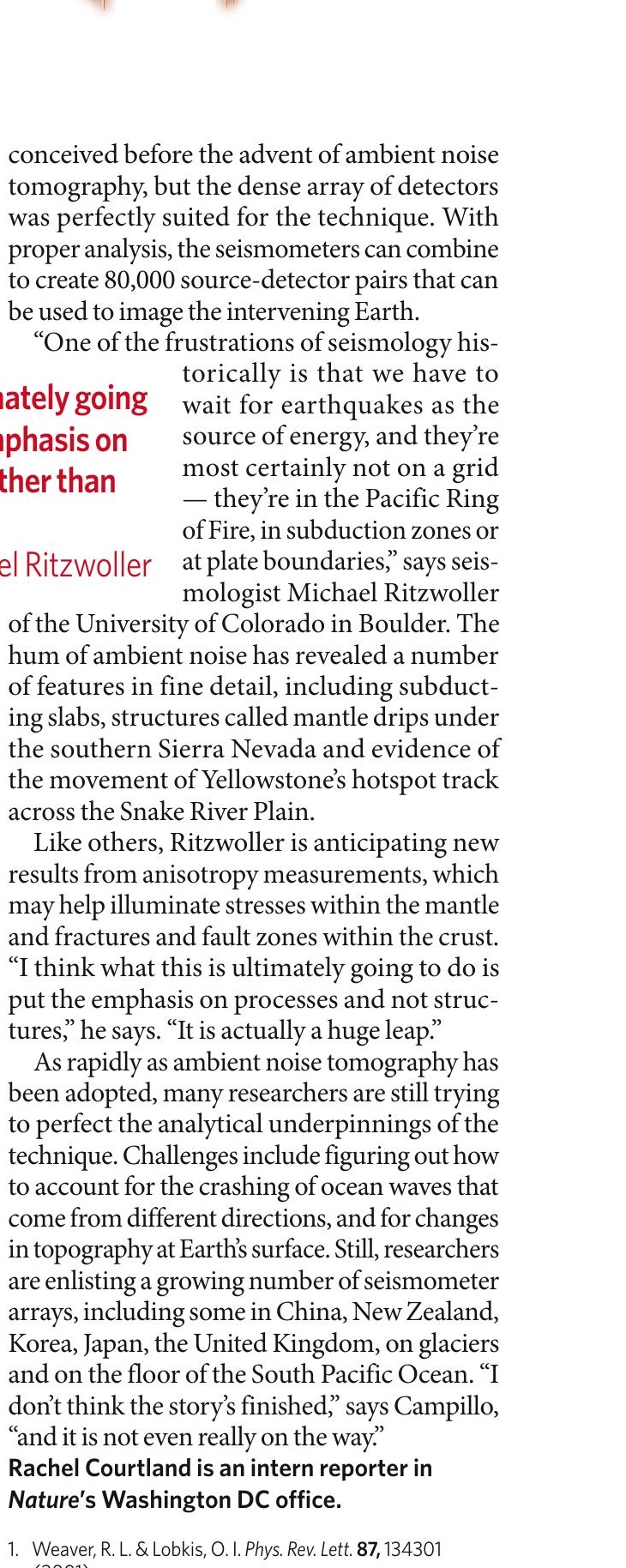

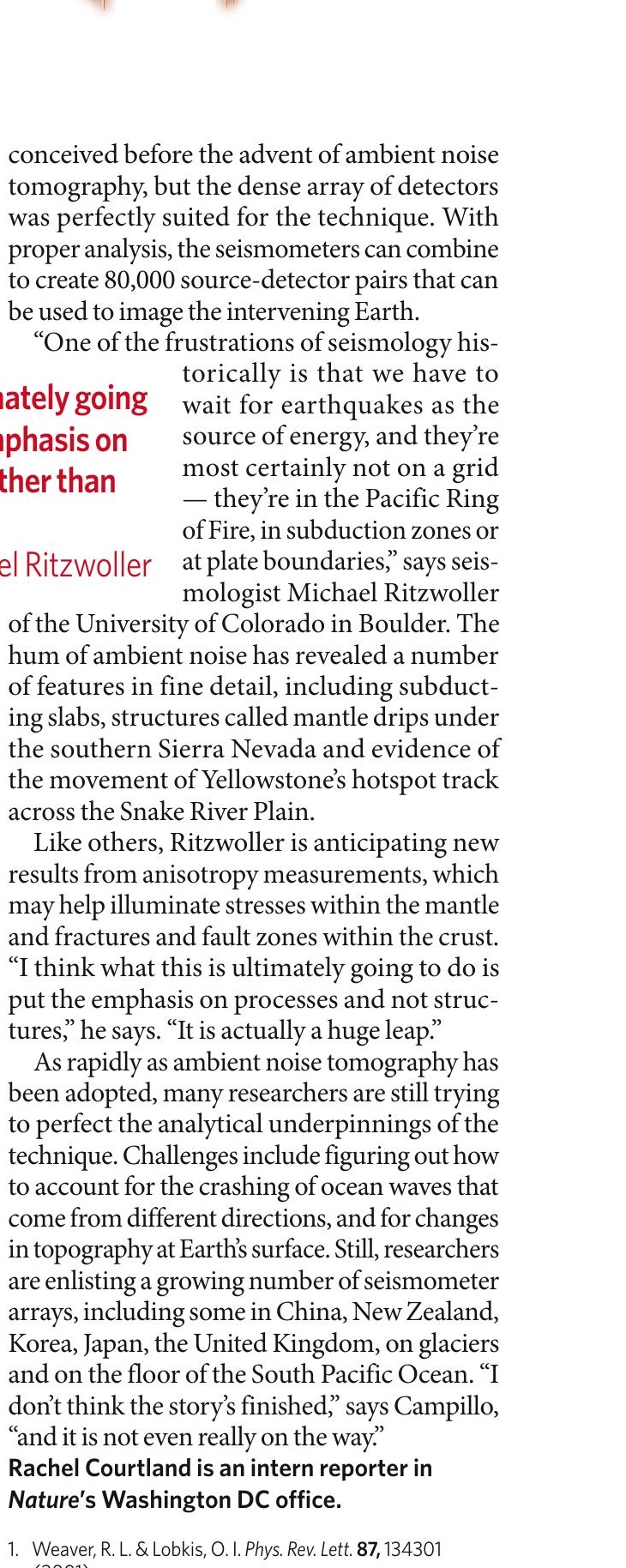

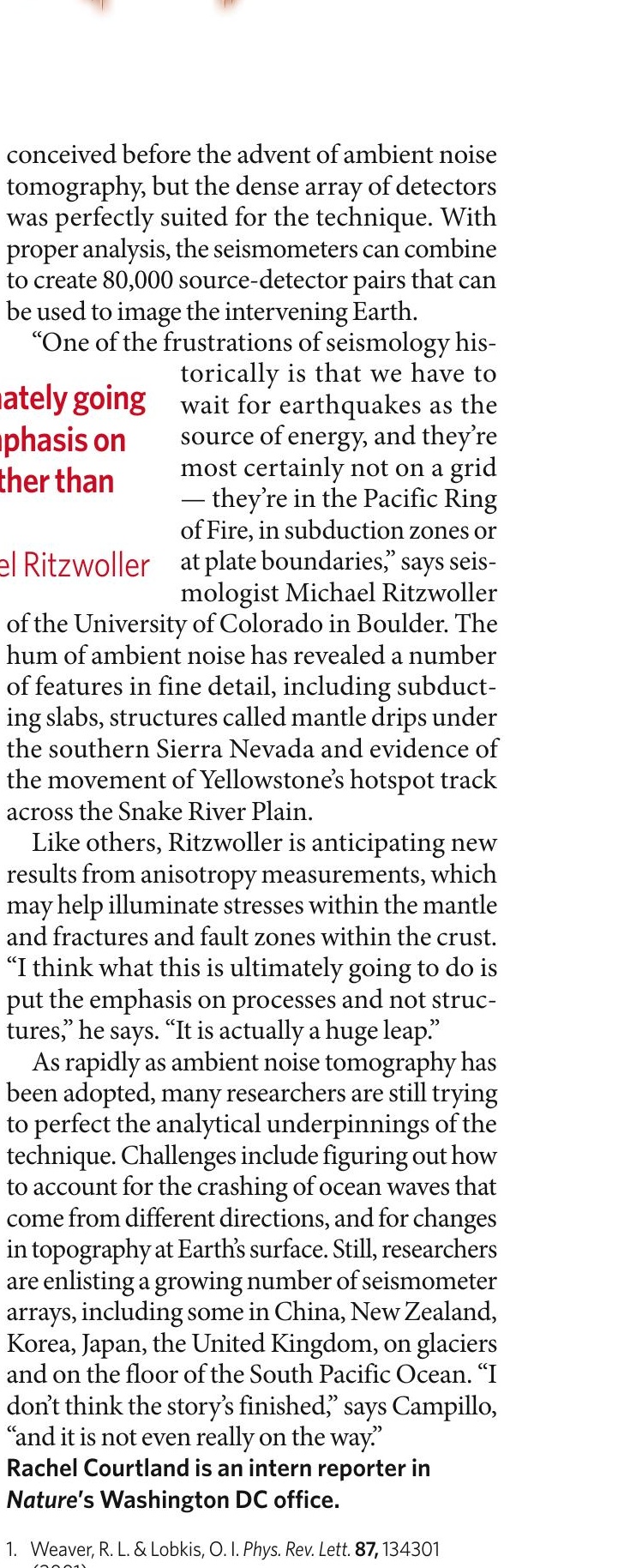

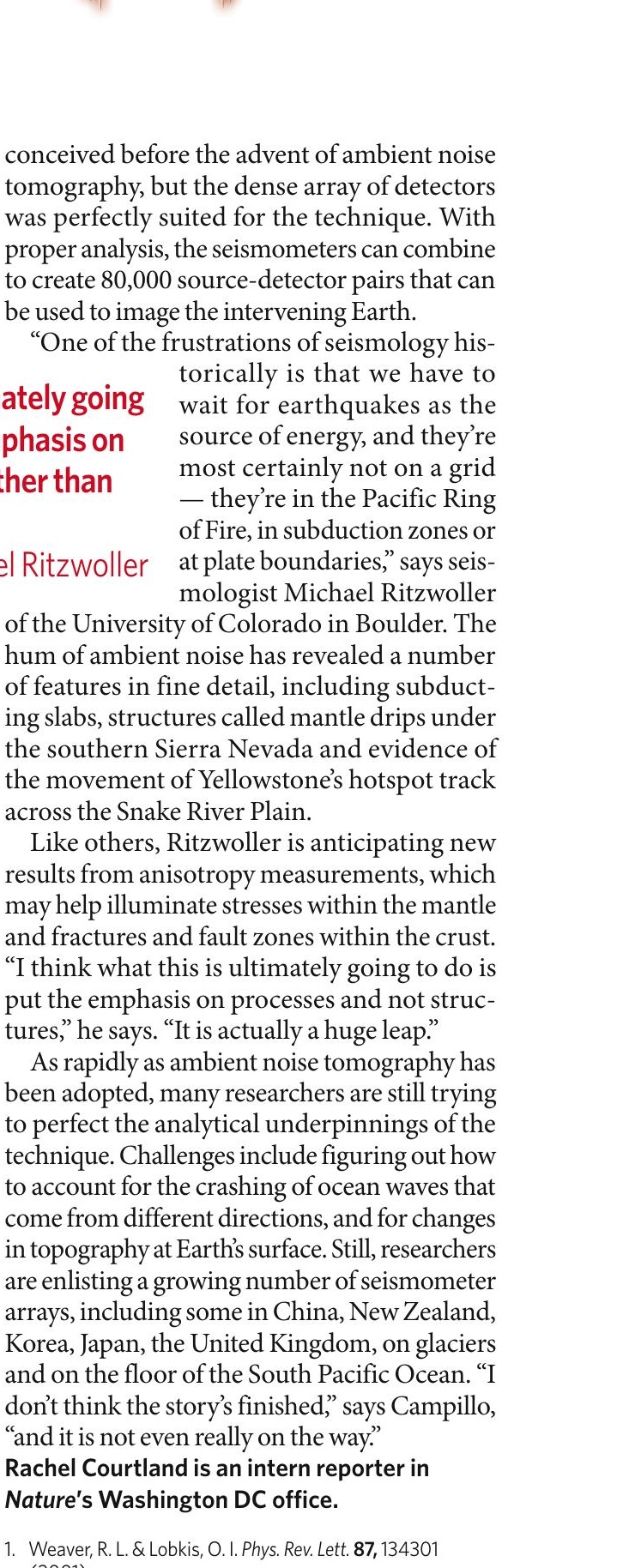

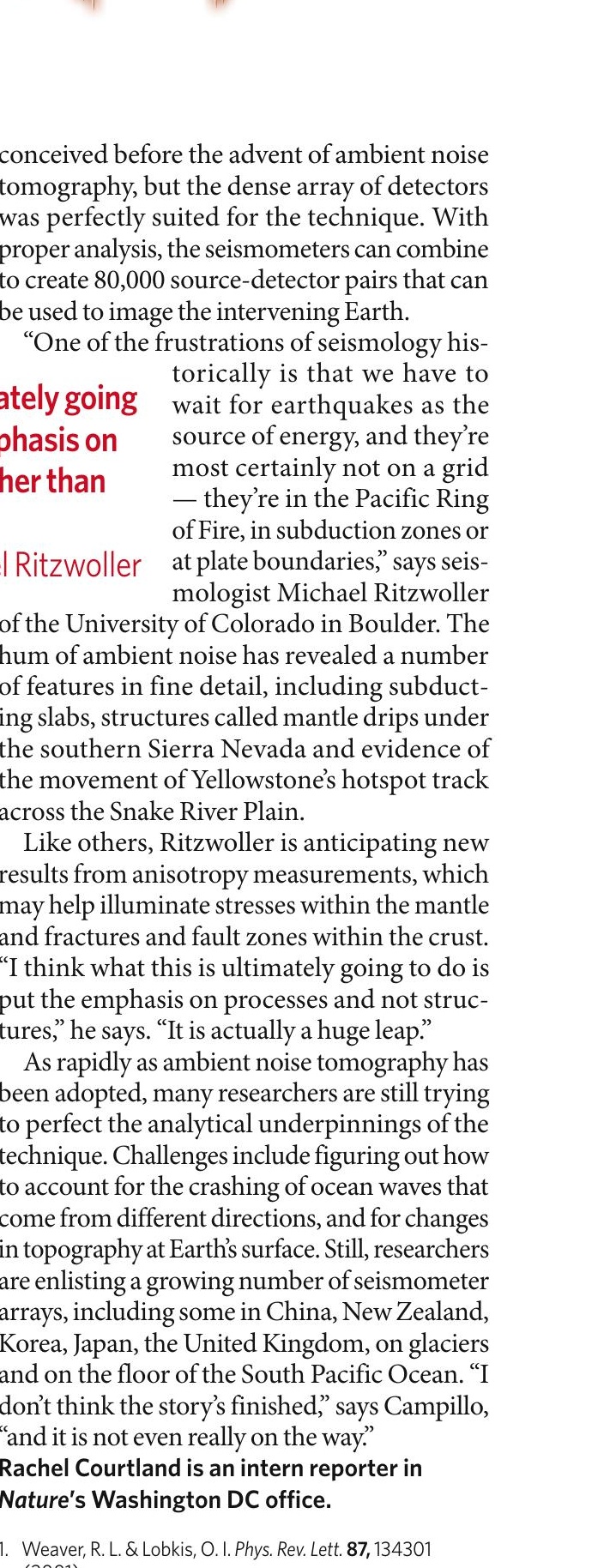

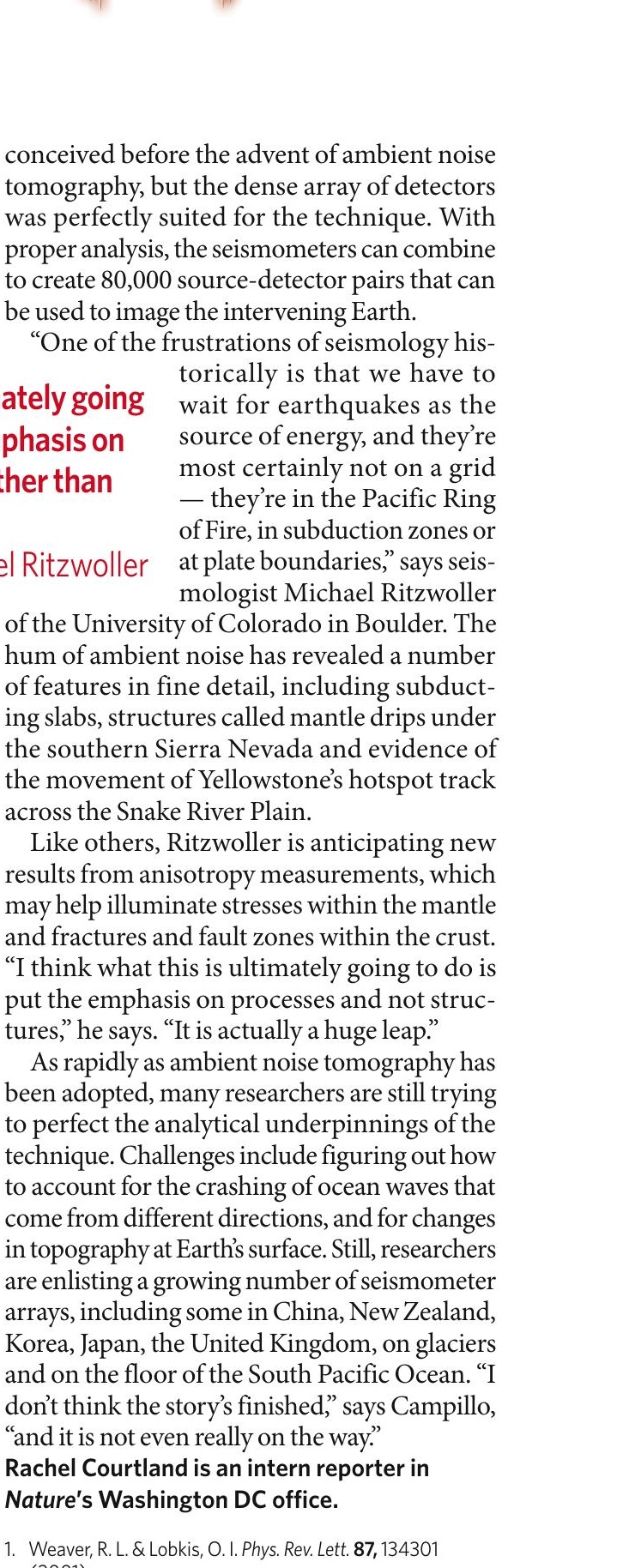

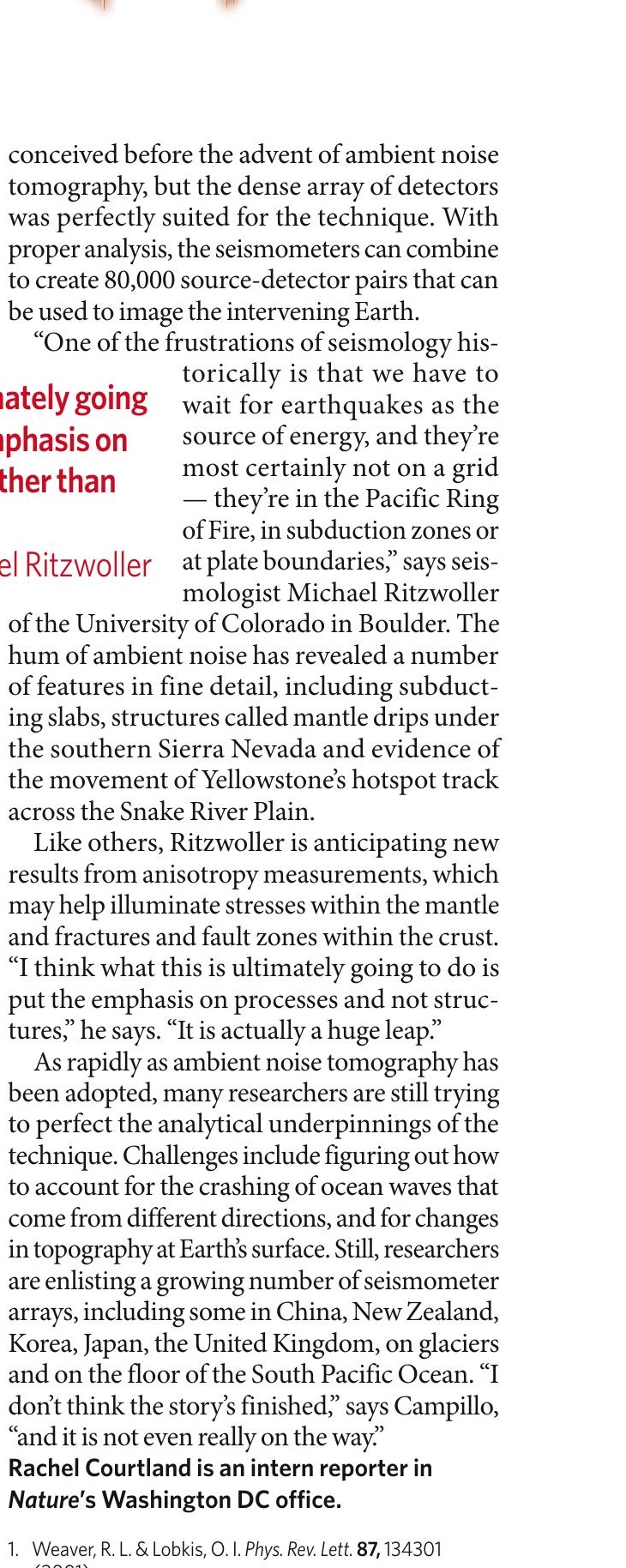

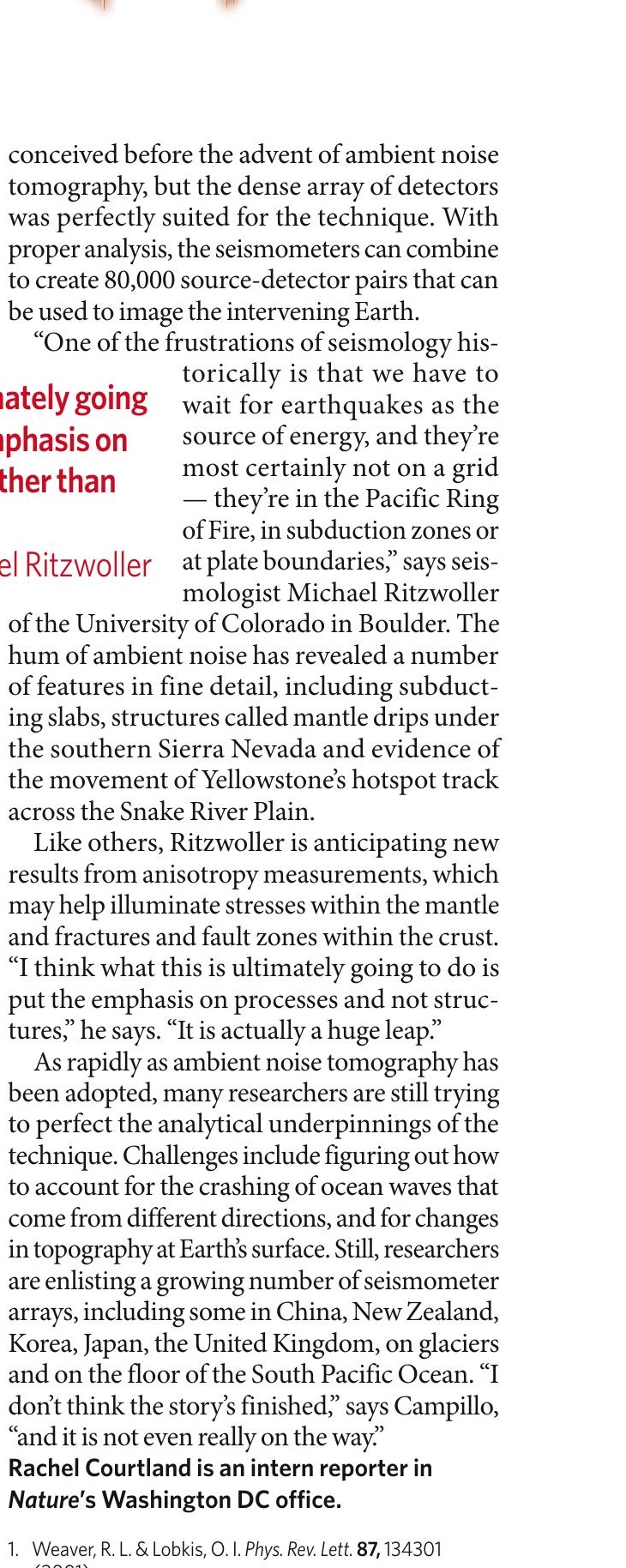

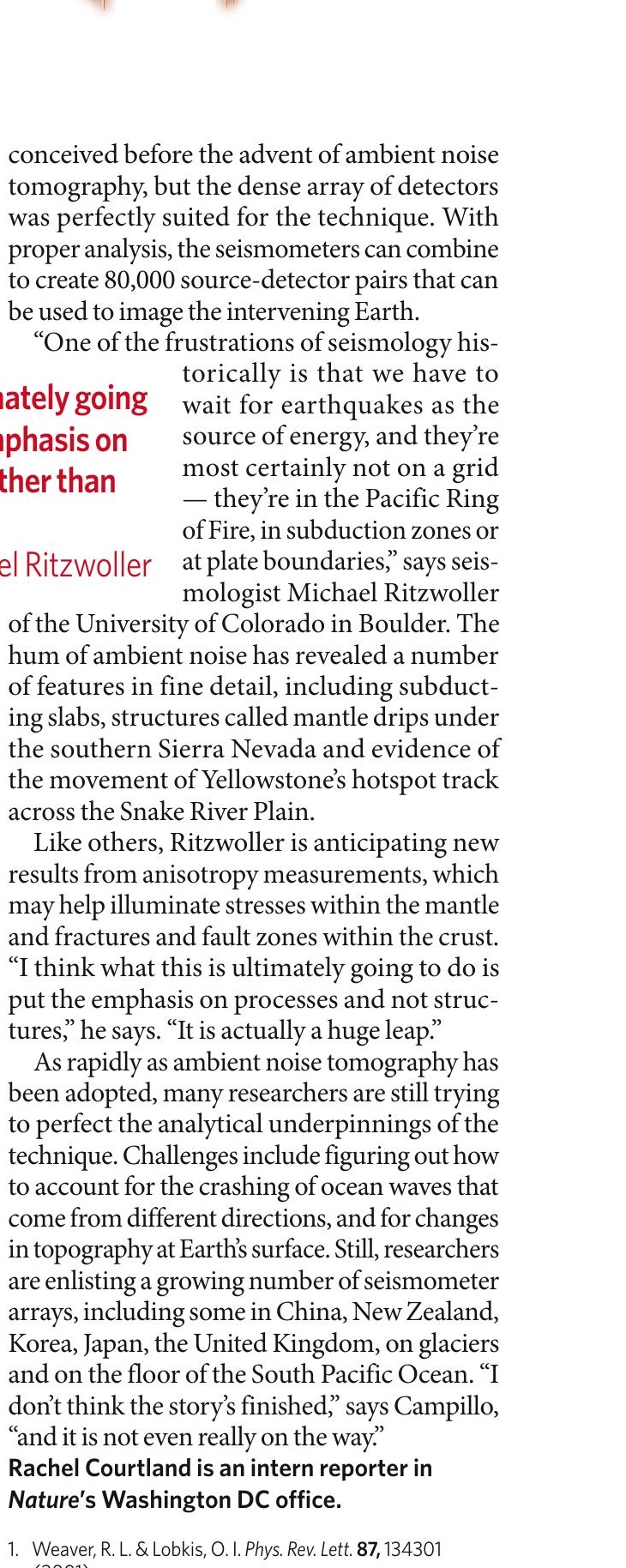

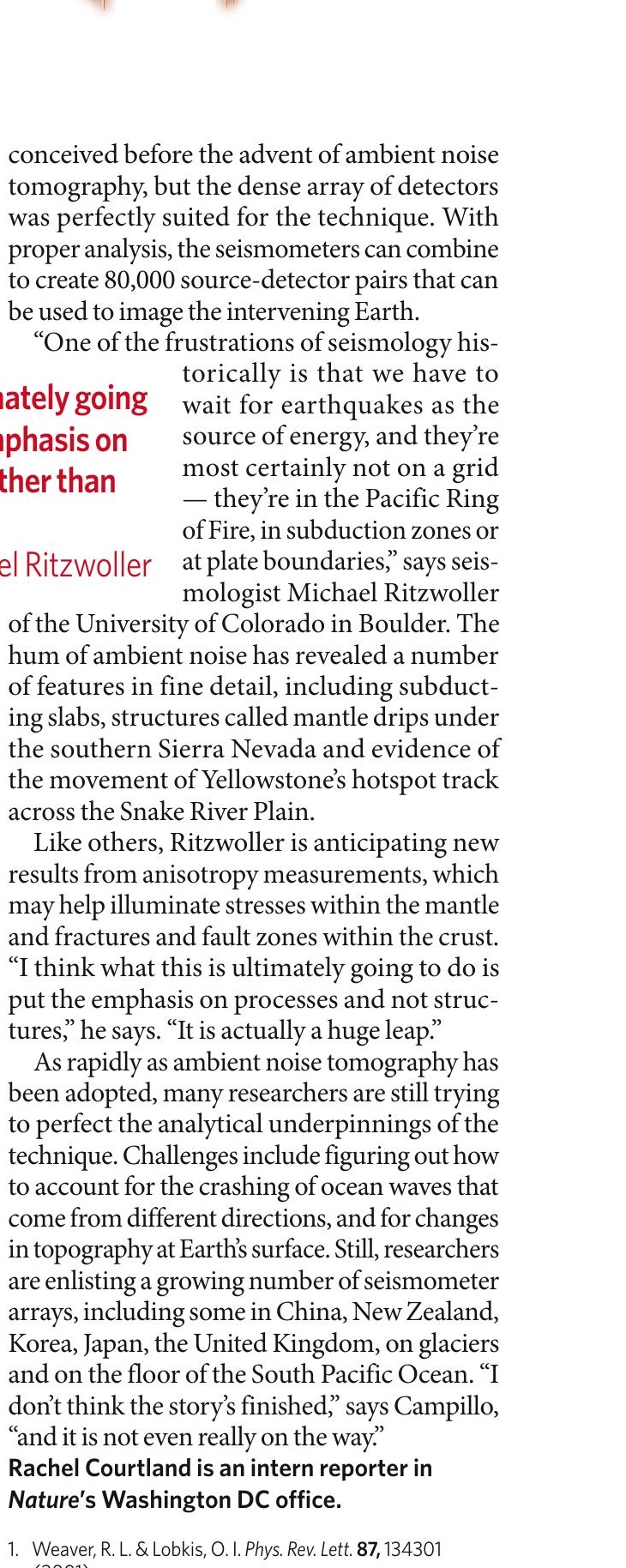

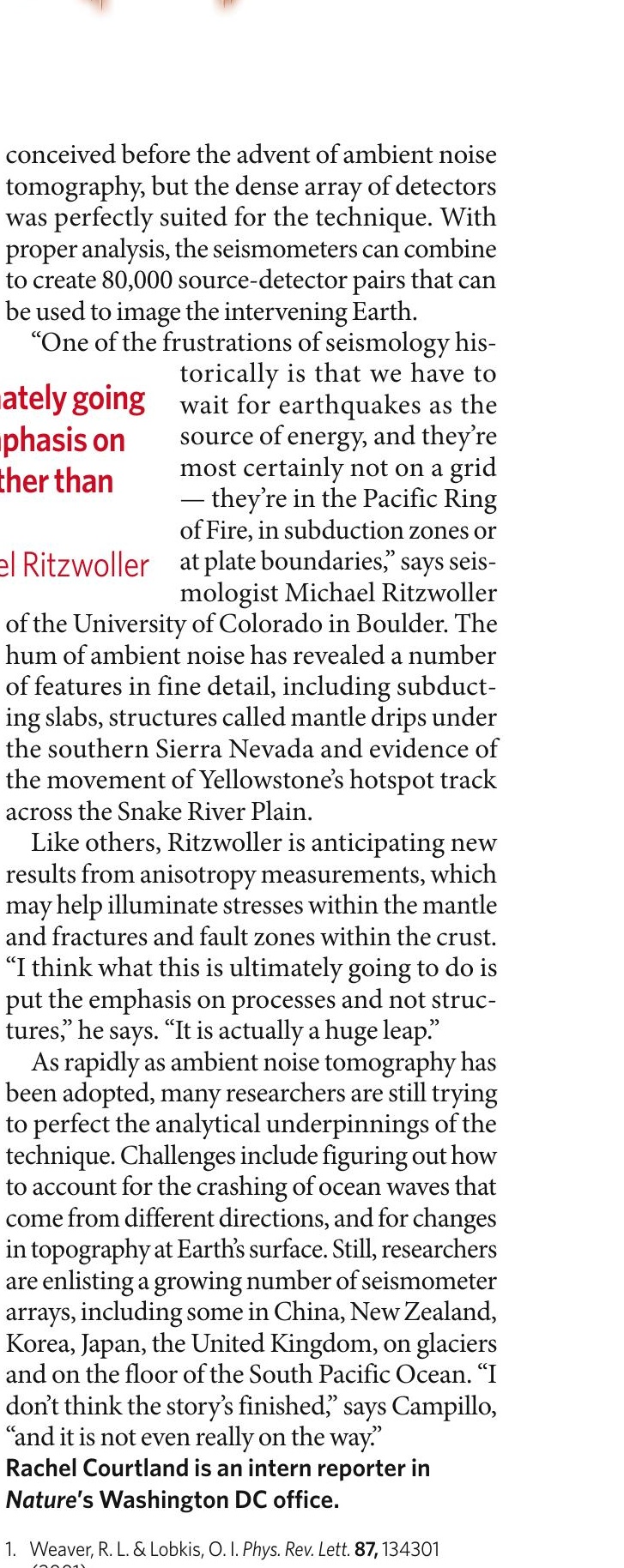

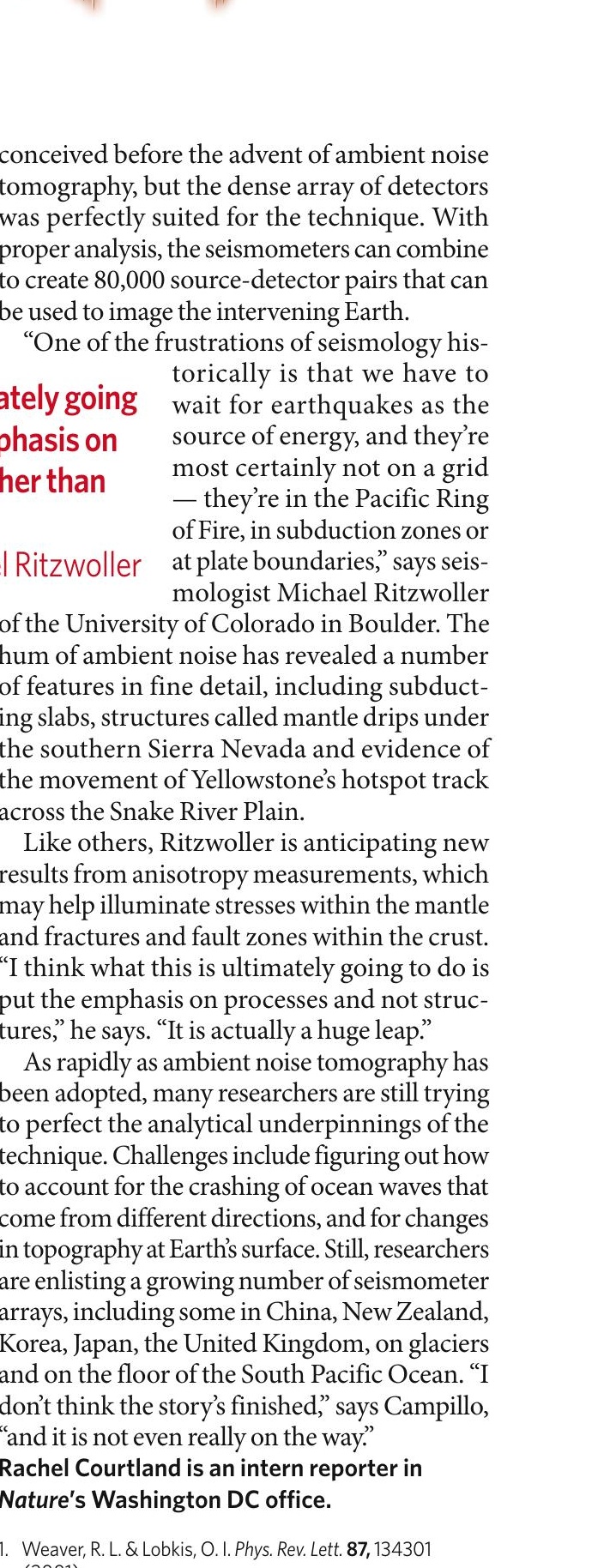

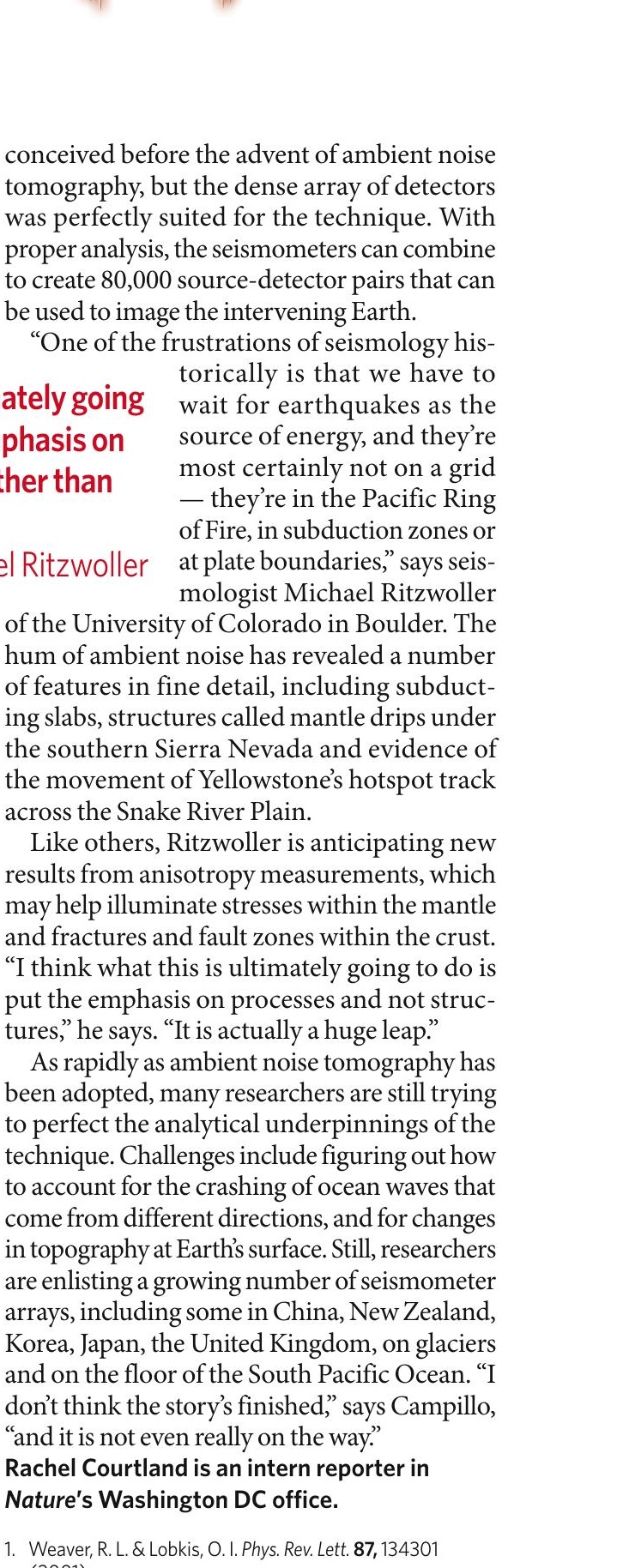

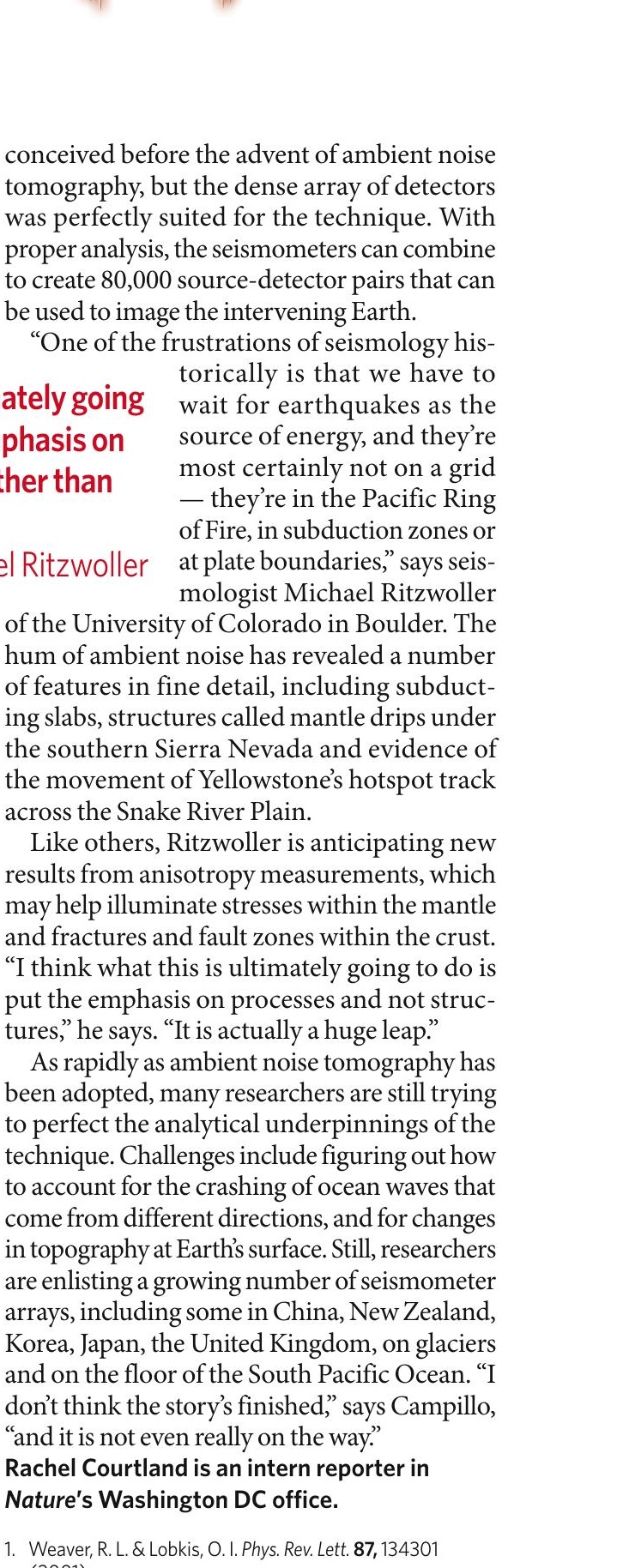

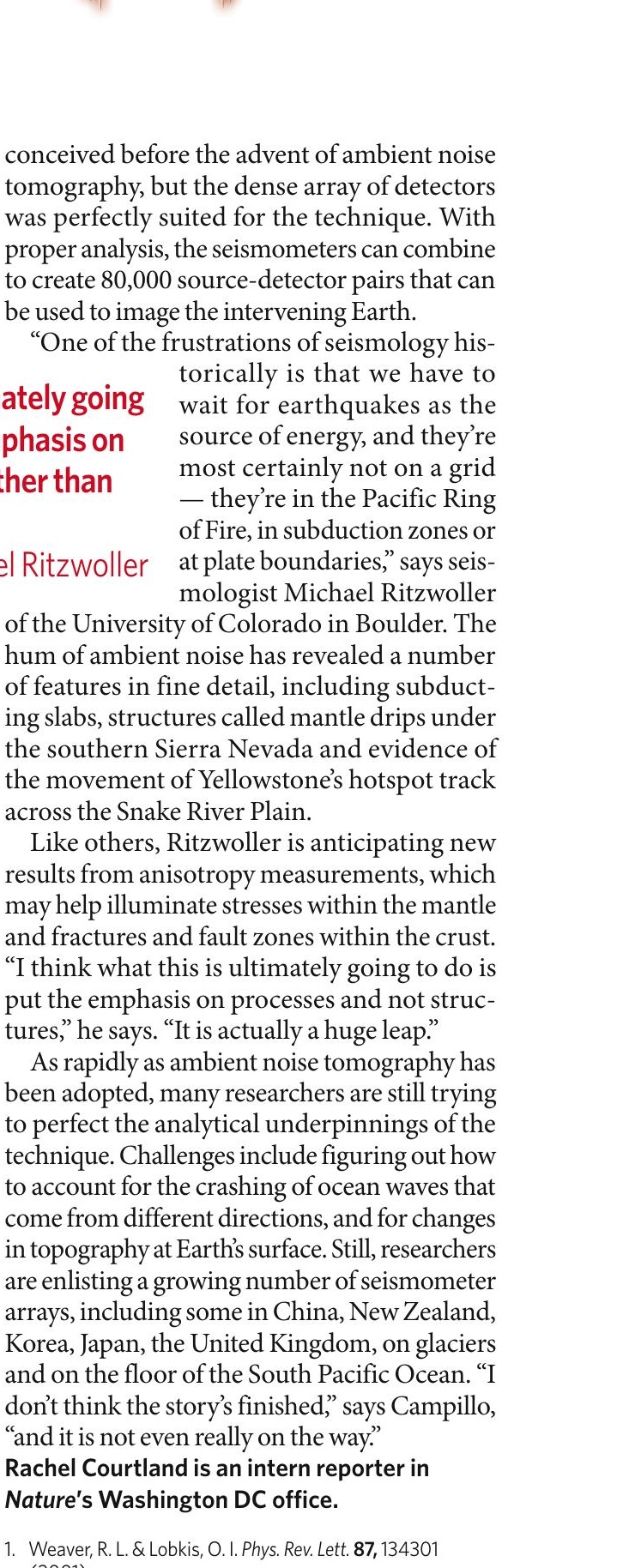

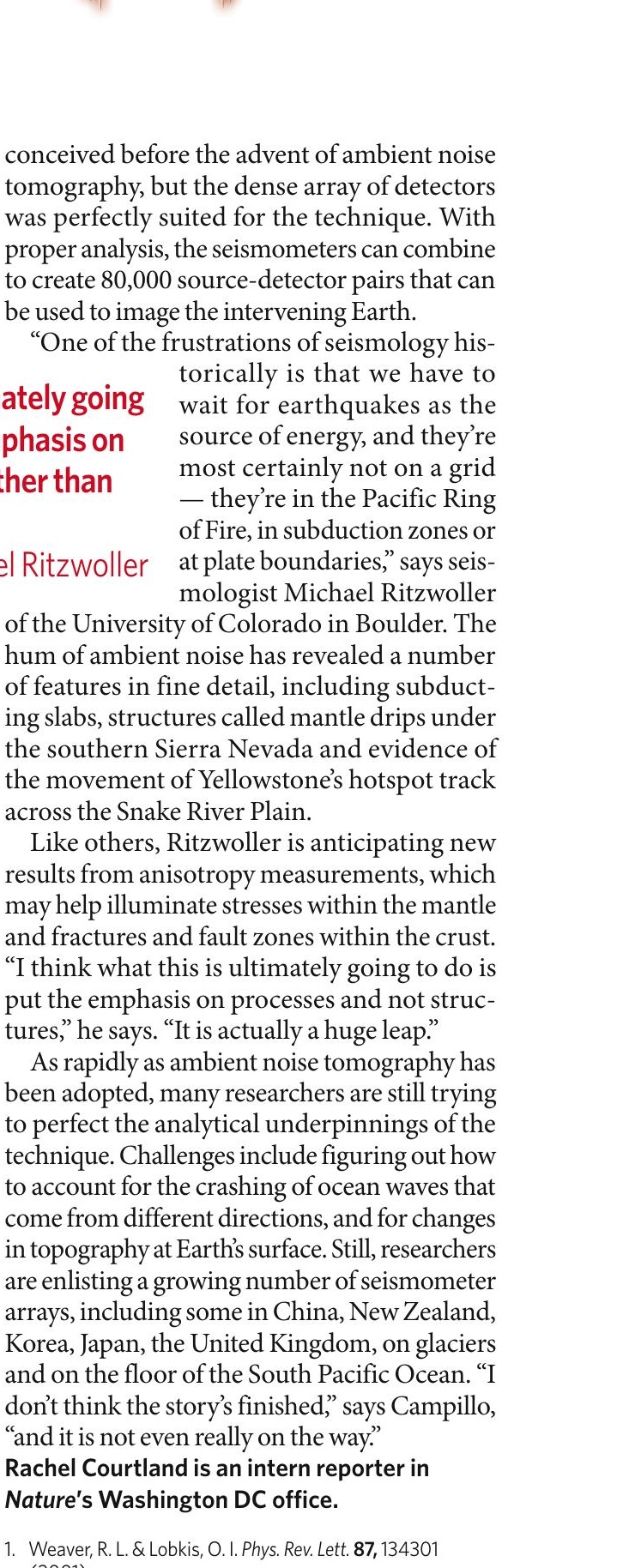

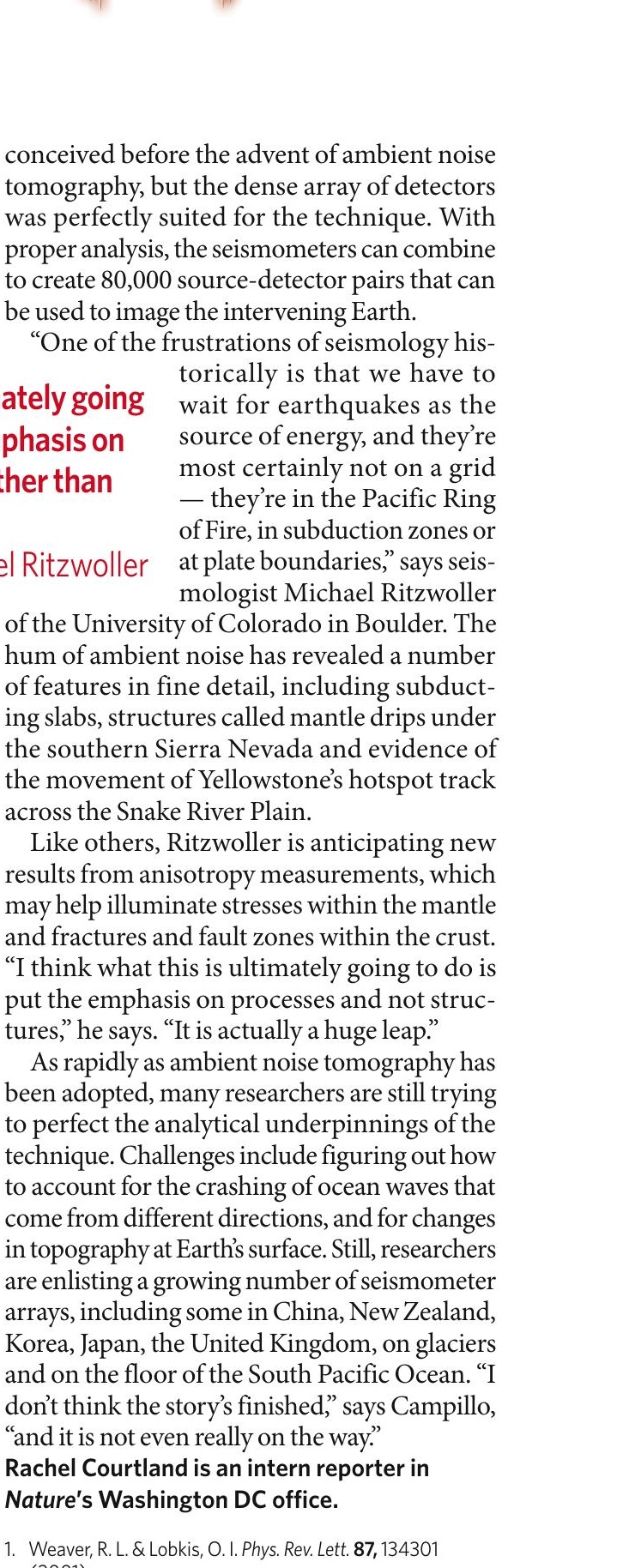

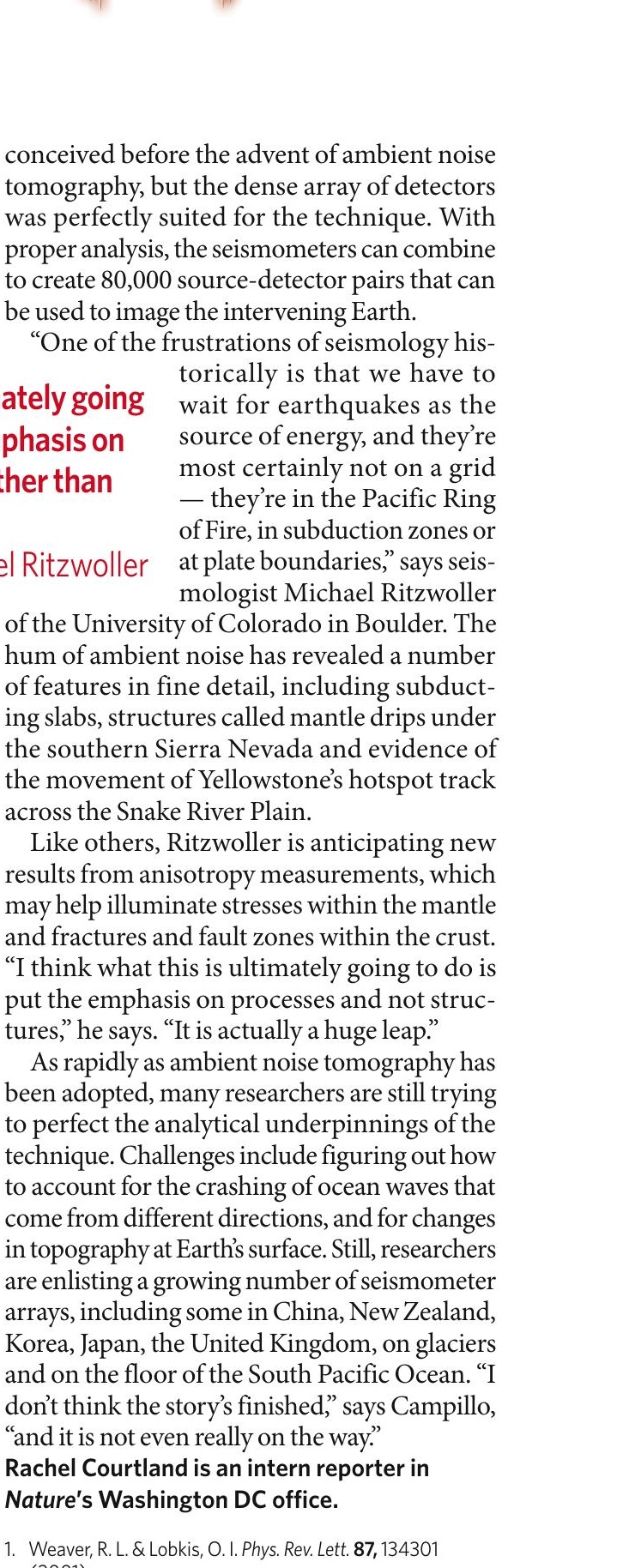

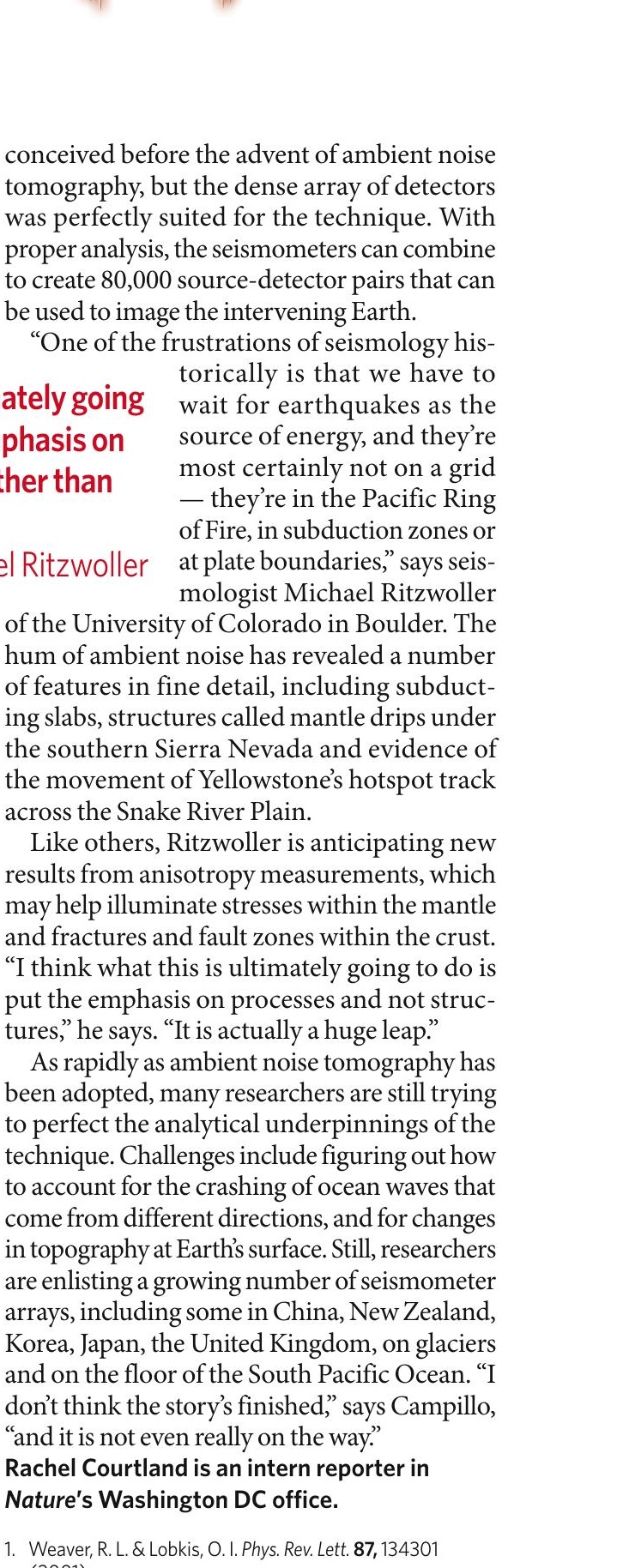

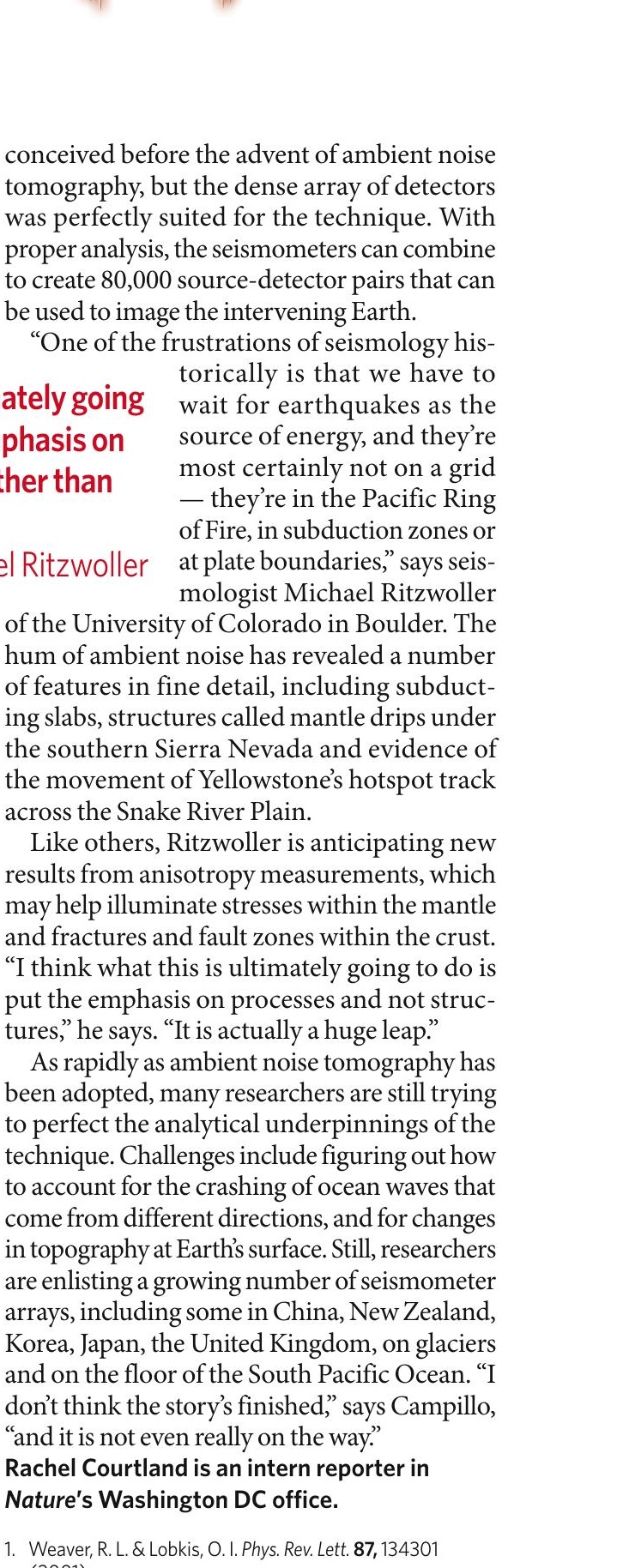

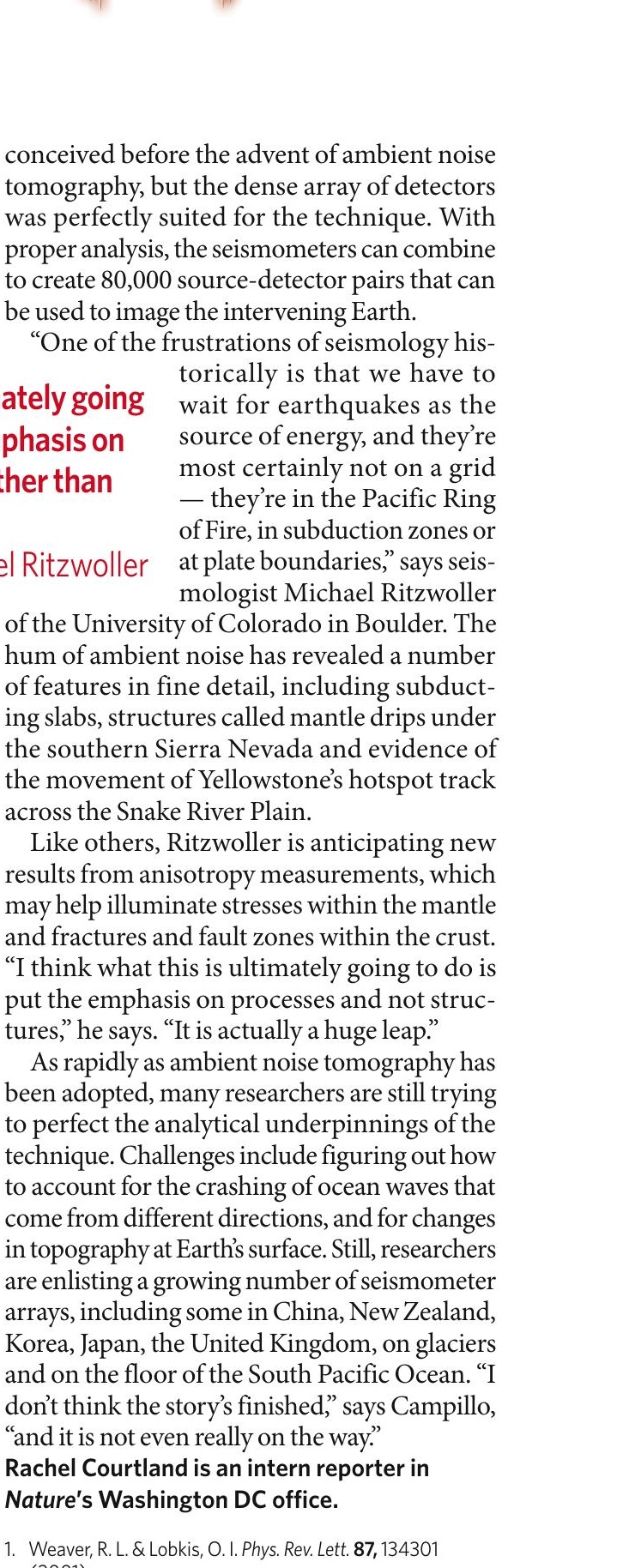

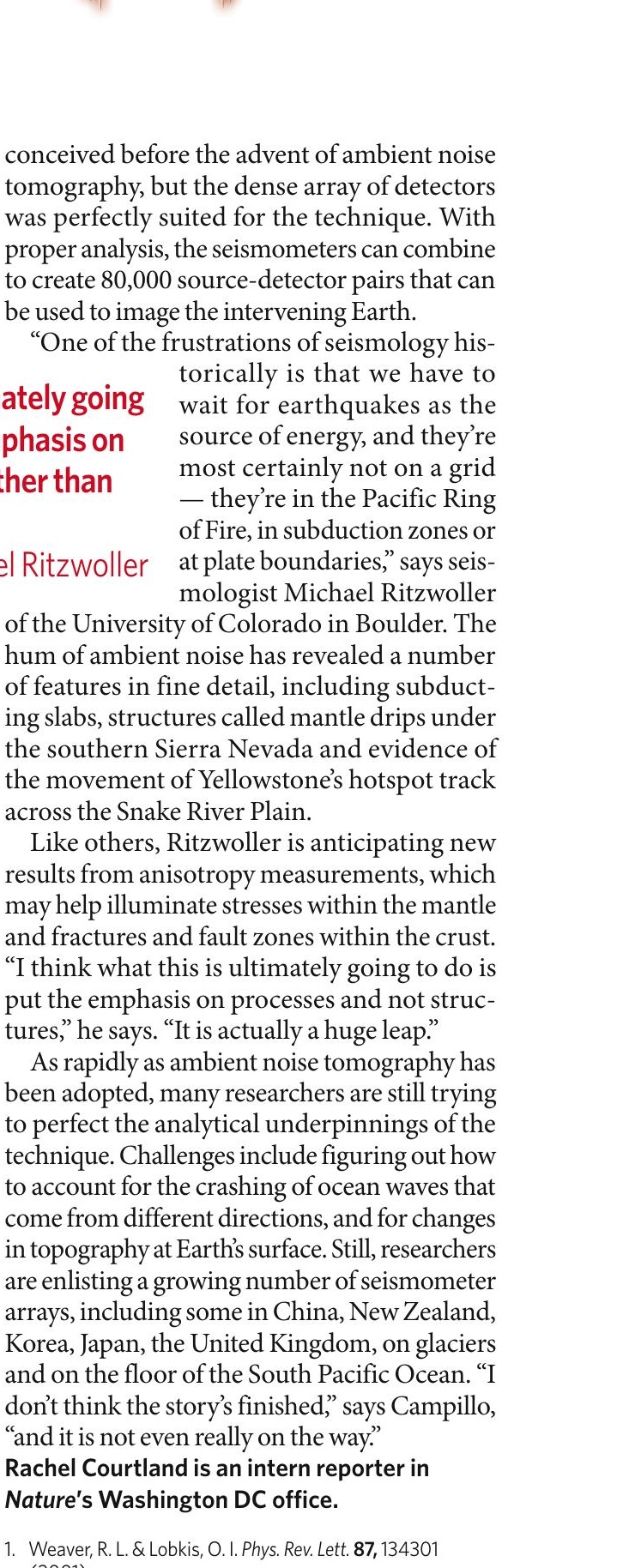

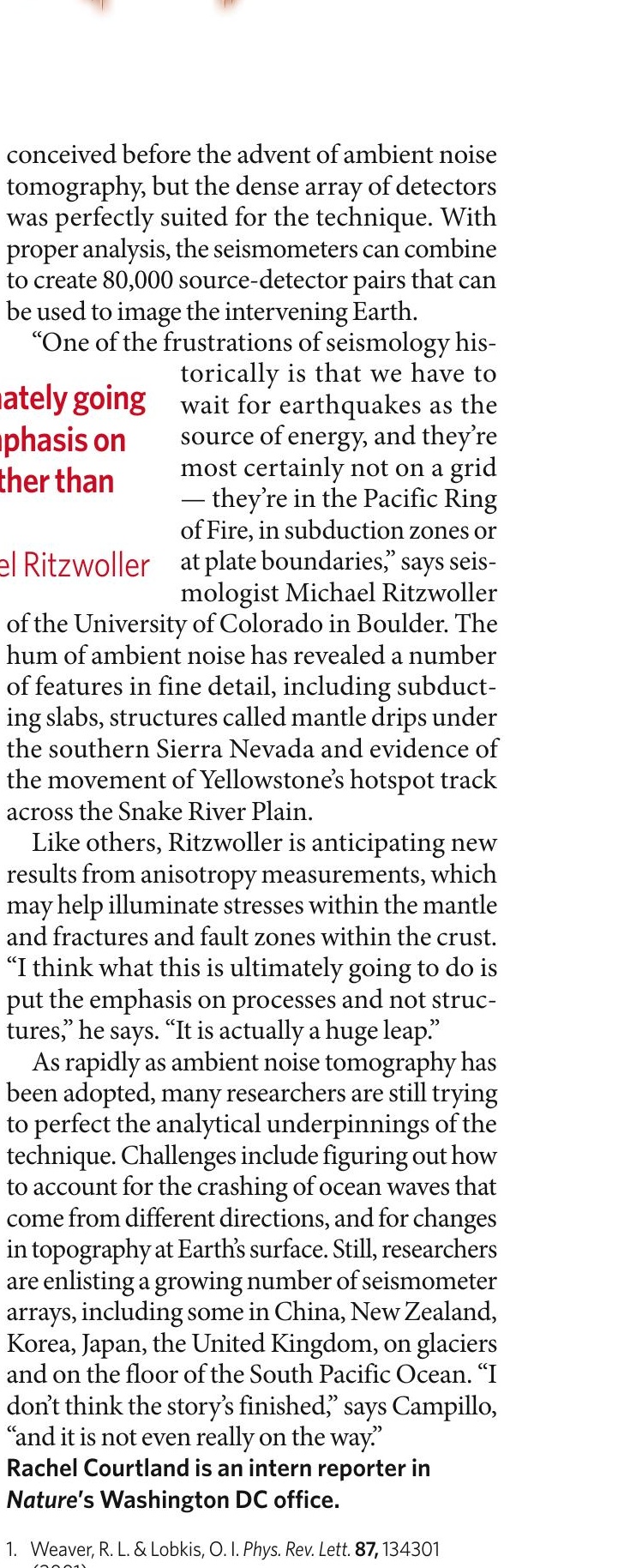

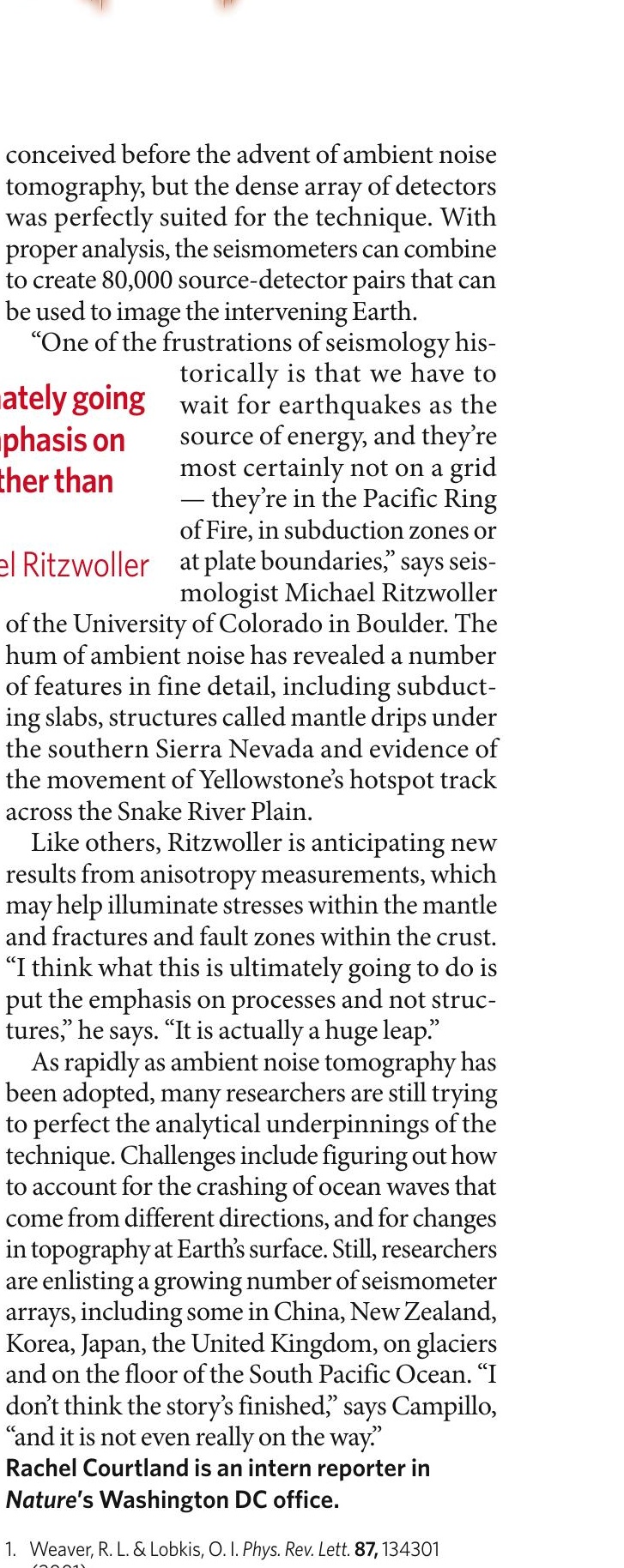

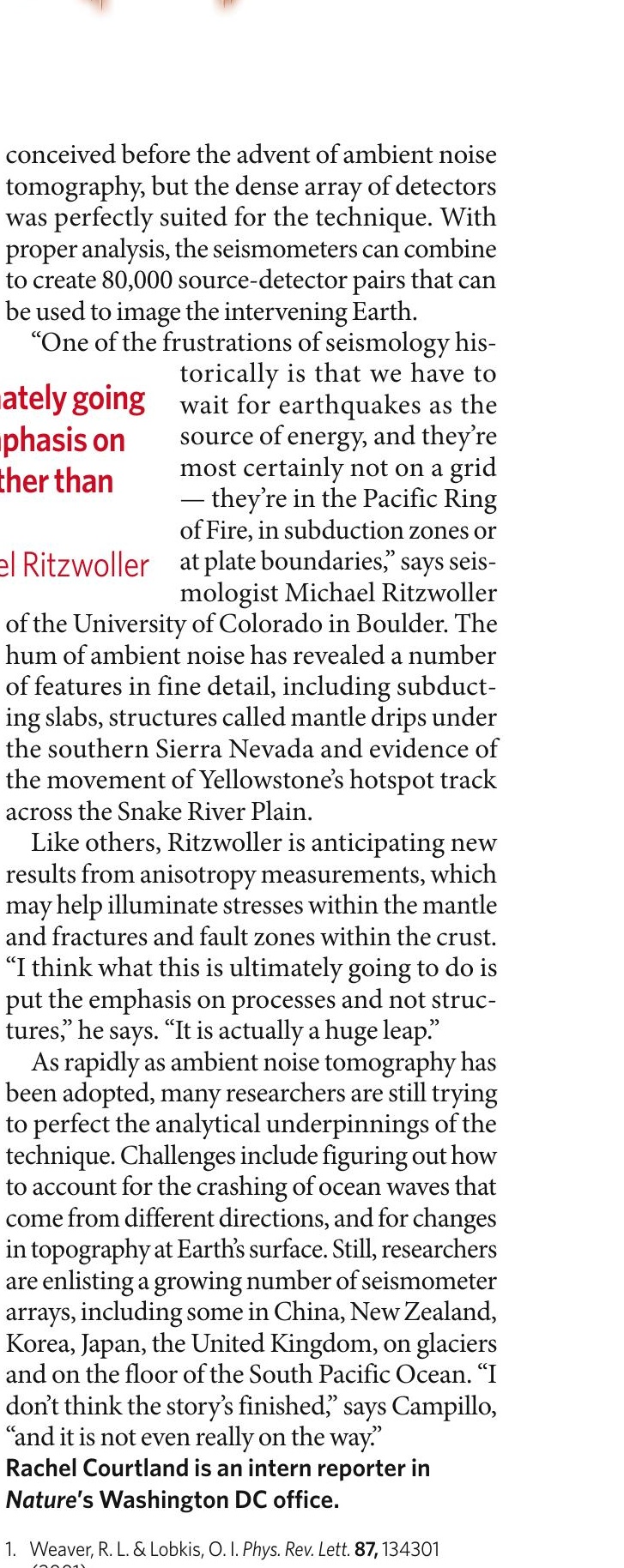

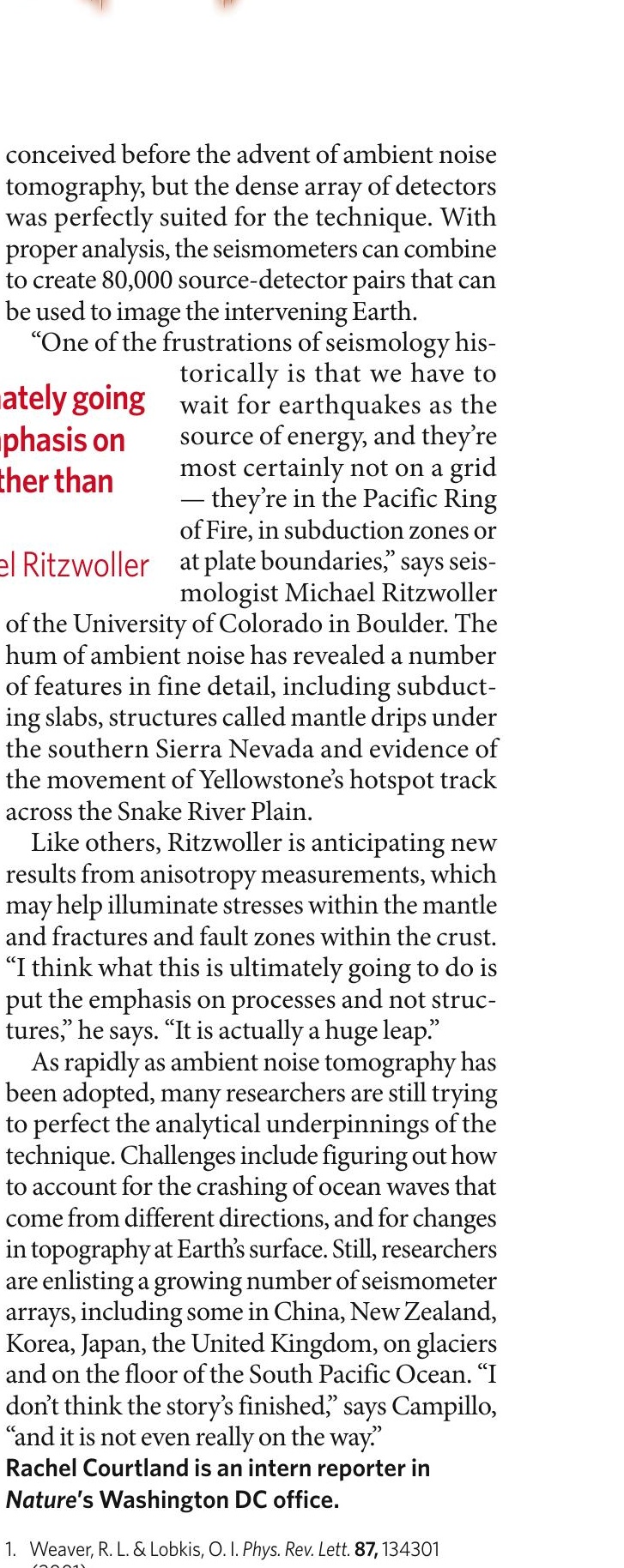
(2001).

2. Paul, A. \& Campillo, M. Eos 82, S21D-0610 (2001).

3. Shapiro, N. M. et al. Science 307, 1615-1618 (2005).

4. Sabra, K. G., Gerstoft, P., Roux, P., Kuperman, W. A. \& Fehler, M. C. Geophys. Res. Lett. 32, L14311 (2005).

5. Yao, H., Beghein, C. \& van der Hilst, R. D. Geophys. J. Int. 173, 205-219 (2008)

6. Brenguier, F. et al. Geophys. Res. Lett. 34, L02305 (2007).

7. Brenguier, F. et al. Nature Geosci. 1, 126-130 (2008).

\section{See Editorial, page 134.}

